Aus der Arbeitsgruppe Endokrinologie

(Prof. Dr. med. W. Wuttke)

der Medizinischen Fakultät der Universität Göttingen

\title{
Wirkung von Endokrinen Disruptoren auf die Tibiametaphyse der ovarektomierten \\ Sprague - Dawley - Ratte
}

\author{
INAUGURAL DISSERTATION \\ zur Erlangung des Doktorgrades \\ der Medizinischen Fakultät \\ der Georg - August - Universität zu Göttingen
}

\author{
vorgelegt von \\ Vera Vossmann \\ aus
}

Hannover

Göttingen 2011 
Dekan:

Prof. Dr. med. C. Frömmel

I. Berichterstatter: Prof. Dr. med. W. Wuttke

II. Berichterstatter: Prof. Dr. rer. nat. Gründker

Tag der mündlichen Prüfung: 08.11.2011 


\section{Inhaltsverzeichnis}

Abkürzungsverzeichnis $\quad 6$

$1 \quad$ Einleitung $\quad 8$

1.1 Endokrine Disruptoren 8

1.1.1 Wirkung und Vorkommen von Endokrinen Disruptoren 8

1.1.2 Die Ultraviolett (UV)-Filter 4-Methylbenzyliden-Camphor (4- MBC) und Octyl-Methoxycinnamat (OMC) 9

1.1.3 4-Nonylphenol 11

1.1.4 Phytoöstrogene 12

$\begin{array}{lll}1.2 & \text { Osteoporose } & 14\end{array}$

1.2.1 Definition der Osteoporose und der Osteopenie 14

1.2.2 Osteoporose in der Postmenopause 14

1.2.3 Tiermodell für postmenopausale Osteoporose 15

1.2.4 Östrogenwirkung am Knochen speziell in der Postmenopause 15

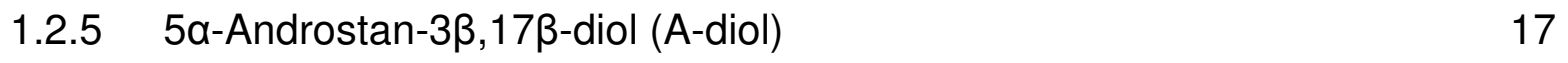

$\begin{array}{lll}1.3 \text { Ziele } & 18\end{array}$

$2 \quad$ Material und Methoden 19

$\begin{array}{lll}2.1 & \text { Tierversuche } & 19\end{array}$

2.1.1 Versuchstiere 19

2.1.2 Ovarektomie der Ratten 19

2.1.3 Applikation der zu untersuchenden Wirkstoffe 20

2.2 Quantitative Computertomographie 21

2.3 Statistische Auswertung 23

3 Ergebnisse $\quad 24$

$\begin{array}{lll}3.1 & \text { Futtermenge } & 24\end{array}$

3.1.1 Durchschnittlicher Tagesfutterverbrauch der Ratten unter 3-monatiger Applikation mit sojafreiem und sojahaltigem Futter von E2, A-diol, NP, 4-MBC und OMC 
3.2.1 Effekte von E2, A-diol, NP, 4-MBC und OMC (3 Monate Applikation mit sojafreiem und sojahaltigem Futter) auf das durchschnittliche Körpergewicht der Ratten 26

3.3 Knochendichtemessung in der Metaphyse der Tibia 28

3.3.1 Effekt von E2, A-diol, NP, 4-MBC und OMC (Applikation 3 Monate mit sojafreiem und sojahaltigem Futter) auf die metaphysäre Spongiosadichte der ovarektomierten Ratte

3.3.2 Effekt von E2, A-diol, NP, 4-MBC und OMC (3 Monate Applikation mit sojafreiem und sojahaltigem Futter) auf die metaphysäre Kortikalisdichte der ovarektomierten Ratte $\quad 30$

3.4 Ergebnisse der Knochenmassemessungen in der Tibiametaphyse 32

3.4.1 Effekt von E2, A-diol, NP, 4-MBC und OMC (3 Monate Applikation mit sojafreiem und sojahaltigem Futter) auf die Spongiosamasse der Metaphyse der ovarektomierten Ratte

3.4.2 Effekt von E2, A-diol, NP, 4-MBC und OMC (3 Monate Applikation mit sojafreiem und sojahaltigem Futter) auf die Kortikalismasse der Metaphyse

3.5 Ergebnisse der Messung der endostalen Fläche in der Metaphyse der Tibia

3.5.1 Effekt von E2, A-diol, NP, 4-MBC und OMC (3 Monate Applikation mit sojafreiem und sojahaltigem Futter) auf die endostale Fläche der Tibiametaphyse

3.5.2 Effekt von E2, A-diol, NP, 4-MBC und OMC (3 Monate Applikation mit sojafreiem und sojahaltigem Futter) auf die Fläche der Kortikalis der Metaphyse der ovarektomierten Ratte

4 Diskussion $\quad 40$

$\begin{array}{lll}4.1 & \text { Ziele } & 40\end{array}$

$\begin{array}{lll}4.2 & \text { Futterverbrauch und Körpergewicht } & 40\end{array}$

4.3 Beurteilung der gemessenen Knochenparameter anhand der Ovx und $17 \beta$-Estradiol Wirkung auf den Knochen 
4.4 Wirkung von A-diol auf den Knochen 43

4.5 Wirkung von Endokrinen Disruptoren 43

4.5.1 Wirkung von Phytoöstrogenen 43

4.5.2 4-Nonylphenol 44

4.5.3 Wirkung der UV-Filter OMC und 4-MBC auf den Knochen 45

$5 \quad$ Zusammenfassung $\quad 46$

$6 \quad$ Literaturverzeichnis 48

$7 \quad$ Abbildungsverzeichnis $\quad 59$

$8 \quad$ Tabellenverzeichnis 60 


\section{Abkürzungsverzeichnis}

Abb.

A-diol

AR

bzw.

${ }^{\circ} \mathrm{C}$

$\mathrm{cm}^{3}$

CRT A

CRT CNT

CRT DEN

d

DHEA

DXA

E2

ED

ER

$\mathrm{ER} \alpha$

$\mathrm{ER} \beta$

ERKO

$\mathrm{Fa}$.

g

high

$\mathrm{Kg}$

low

4-MBC

$\mathrm{mg}$

$\mathrm{mm}$

$\mathrm{mm}^{2}$

mRNA

NP

OMC

Ovx
Abbildung

$5 \alpha$-Androstan-3 $\beta$, 17 $\beta$-diol

Androgenrezeptor

beziehungsweise

Grad Celsius

Kubikzentimeter

Fläche der Kortikalis

Kortikalismasse

Kortikalisdichte

Tag

Dehydroepiandrosteron

Dual-Energy-X-Ray-Absorptiometrie

$17 \beta$ - Estradiol

Endokrine Disruptoren

Östrogenrezeptor

Östrogenrezeptor alpha

Östrogenrezeptor beta

Östrogenrezeptor-Knockout-Maus

Firma

Gramm

hohe Dosierung

Kilogramm

niedrige Dosierung

4-Methylbenzyliden-Camphor

Milligramm

Millimeter

Quadratmillimeter

messenger-Ribonukleinsäure

4-Nonylphenol

Octyl-Methoxycinnamat

Ovarektomie 


$\begin{array}{ll}\text { ovx } & \text { ovarektomiert } \\ \% & \text { Prozent } \\ \text { pixels } & \text { Bildpunkte } \\ \text { pQCT } & \text { peripherer quantitativer Computertomograph } \\ \text { prae Ovx } & \text { vor Ovarektomie } \\ \text { ROI } & \text { region of interest } \\ \text { SEM } & \text { Standardfehler des Mittelwertes } \\ \text { SERM } & \text { Selektive Östrogenrezeptor-Modulatoren } \\ \text { soy } & \text { Soja } \\ \text { TRAB A } & \text { endostale Fläche } \\ \text { TRAB CNT } & \text { Spongiosamasse } \\ \text { TRAB DEN } & \text { Spongiosadichte } \\ \text { u.a. } & \text { unter anderem } \\ \text { UV } & \text { Ultraviolett } \\ \text { z.B. } & \text { zum Beispiel }\end{array}$




\section{$1 \quad$ Einleitung}

\subsection{Endokrine Disruptoren}

\subsubsection{Wirkung und Vorkommen von Endokrinen Disruptoren}

Endokrine Disruptoren (ED) sind exogene Wirkstoffe, die mit Synthese, Sekretion, Transport, Bindung, Wirkung oder Elimination der im Körper vorhandenen natürlichen Hormone interferieren können. Eine intakte Funktion der körpereigenen Hormone ist aber für die Aufrechterhaltung des hormonellen Gleichgewichtes, für Fortpflanzung und Entwicklung notwendig (Dankwardt 1998). Chemikalien, die endokrin wirksam sind, werden in vielen Produkten gefunden, u.a. in Pestiziden (Colborn 2006, Hammond et al. 1979), in Industriechemikalien (Longnecker et al. 1997), in Haushaltsreinigern, Tensiden (Han et al.2002) und Plastik (Soto et al.1991), sowie in Kosmetikprodukten (Schlumpf et al. 2004b).

Umweltchemikalien können das Hormonsystem durch verschiedene Wege beeinflussen. Sie lösen durch Bindung an Sexualhormonrezeptoren und deren Aktivierung Hormonwirkungen aus. Ebenso können dadurch auch körpereigene Hormone blockiert werden. Sie vermögen aber auch die Synthese und den Abbau von Steroidhormonen zu beeinflussen, indem sie Enzymaktivitäten und daraus resultierend die Hormonrezeptorkonzentration in Zielorganen verändern (Terasaka et al. 2004, Tapiero et al. 2002). Der Mensch ist den ED durch die Nahrungsaufnahme, Inhalation durch die Luft und Hautabsorption ausgesetzt (Nicolopoulou-Stamati und Pitsos 2001). Umweltchemikalien wirken toxisch auf Fortpflanzungs- und Entwicklungsprozesse. Für den Menschen und bei verschiedenen Tierarten wird als Folge der Belastung durch ED eine Zunahme von Reproduktionsstörugen angenommen (Danzo 1998, Schlumpf und Lichtensteiger 1996), unter anderem die Abnahme der Spermienqualität beim Menschen (Carlsen et al.1992) und die Beeinträchtigung der Steroidhormon-Produktion im Ovar durch Störung der Granulosa-Zellen (Heimler et al.1998). ED beeinträchtigen den Transport (Cheek et al. 1999) und die Biosynthese der Schilddrüsenhormone (Schmutzler et al.2004).

Natürliche Östrogene entfalten ihre Wirkungen im Körper durch Bindung an spezifische Steroidhormonrezeptoren (McDonnell und Norris 2002). ED besitzen strukturell zum Teil große Ähnlichkeit zu Steroidhormonen. Es konnte in Versuchen gezeigt werden, dass eine 
Reihe von Umweltchemikalien die Fähigkeit besitzt, die Wirkung von endogenem 17ßEstradiol (E2) nachzuahmen, und zwar durch Bindung und Aktivierung des Östrogenrezeptors (ER) (Paris et al.2002, Kuiper et al.1998,Gaido et al.1997).

\subsubsection{Die Ultraviolett- (UV) Filter 4-Methylbenzyliden-Camphor (4- MBC) und Octyl-Methoxycinnamat (OMC)}

UV-Filter bilden eine neuere Klasse der Endokrinen Disruptoren. Sie bestehen aus organischen Chemikalien, die Licht im UVA- und UVB-Bereich absorbieren. UV-Filter sind weit verbreitet, da sie unter anderem vor allem in Sonnenschutzmitteln, aber auch in Kosmetika, Haarpflegeprodukten, Folien, Waschpulver und als Zusätze in Plastikprodukten eingesetzt werden (Schlumpf et al. 2004b). Sie sind lipophil und neigen daher zur Bioakkumulation.

Sonnenschutzmittel werden häufig eingesetzt, um Sonnenbrand und Hautkrebs zu verhindern. Hayden et al. zeigten, dass Sonnenschutzmittel nach dem Auftragen absorbiert werden (Hayden et al.1997). In den Fischen deutscher Seen konnten UVFiltersubstanzen nachgewiesen werden (Nagtegaal et al.1997). Der Mensch ist den UVFiltern also durch dermale Applikation und die Nahrungskette ausgesetzt.

In vivo und in vitro konnte dosisabhängige Östrogenität für eine Reihe von UV-FilterSubstanzen nachgewiesen werden, insbesondere für die in dieser Arbeit untersuchten Stoffe 4-MBC und OMC.

Beide oben genannten UV-Filter bewirken nach oraler und dermaler Applikation in der juvenilen Ratte eine Erhöhung des Uterus-Gewichts, wobei sich ein signifikanter Anstieg unter oraler Gabe von $119 \mathrm{mg} / \mathrm{Kg} / \mathrm{d}$ 4-MBC zeigt, dieser sogenannte Uterotrophic Assay ist ein Säugetier-in-vivo-Modell für östrogene Wirkung (Odum et al. 1997). 4-MBC und OMC aktivieren Östrogenrezeptor alpha (ERa) (Gomez et al. 2005). Bei östrogensensitiven Brustkrebszellen MCF-7 bewirkte die Inkubation mit 4-MBC und OMC eine Zellproliferation ebenso wie unter 17ß-Estradiol-Inkubation (Schlumpf et al.2001). Darüber hinaus aktiviert 4-MBC Alkalische Phosphatase in der endometrialen Adenokarzinomzelllinie Ishikawa, ein in-vitro-Testsystem für Östrogenität (Mueller et al. 2003).

4-MBC bindet kompetitiv an Östrogenrezeptoren, wobei sich eine Präferenz für Östrogenrezeptor beta (ER $\beta$ ) zeigte (Schlumpf et al. 2004a). Exposition von 4-MBC 
verursacht ebenfalls Veränderungen in der Expression von Östrogen-regulierten Genen (Durrer et al. 2005).

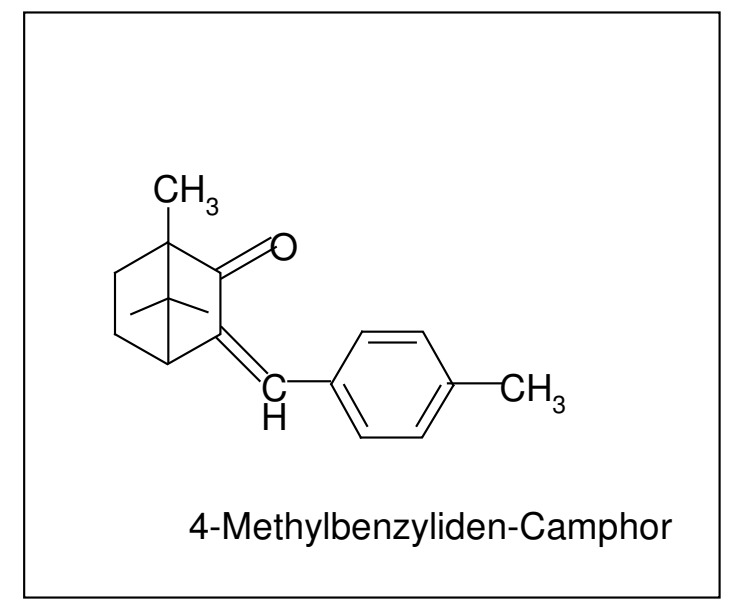

Abbildung 1: Strukturformel 4-MBC

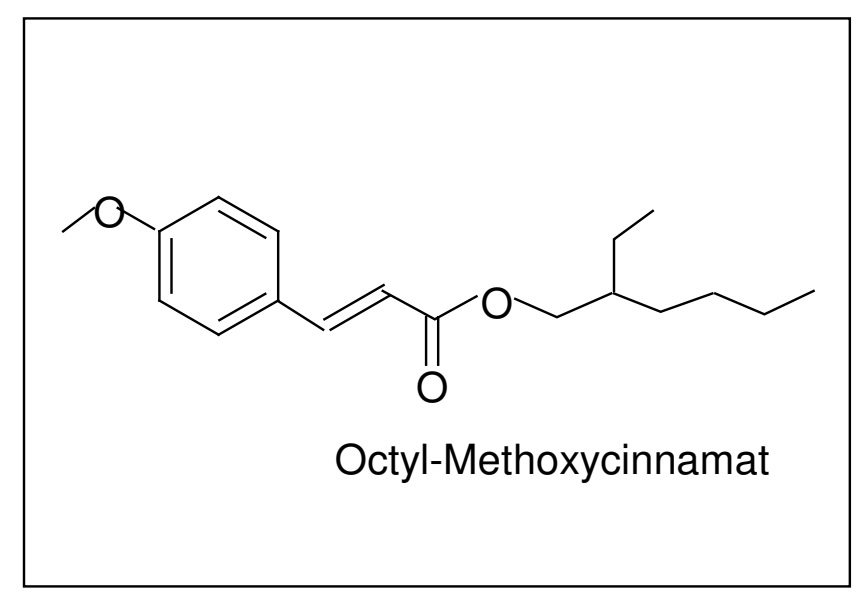

Abbildung 2: Strukturformel OMC 


\subsubsection{4-Nonylphenol}

4-Nonylphenol (NP) ist eine Alkylphenol-Verbindung, die hauptsächlich in der chemischen Industrie eingesetzt wird. Weit verbreitet wird es ebenfalls in Form der NonylphenolPolyethoxylate zur Herstellung von Dispersionsmitteln und Tensiden verwendet (Müller und Schlatter 1998). Darüber hinaus dient NP als Stabilisator und Antioxidans bei der Plastikherstellung für Polyvinylchlorid oder Polystyrene.

Umweltbelastung durch NP entsteht durch den Abbau der Nonylphenol-Polyethoxylate und aus direkter Freisetzung aus Plastikprodukten (Zalko et al. 2002, Doerge et al. 2002). Exposition für den Menschen erfolgt durch die Nahrungsaufnahme. NP ist in diversen häufig verwendeten Lebensmitteln nachzuweisen (Guenther et al. 2002), da es aus Polyvinylchloridverpackungen in die Nahrung abgesondert wird (Inoue et al. 2001). Weiterhin konnten Spuren im Trinkwasser (Bennie 1999) und Abwasser (Ying et al. 2002) nachgewiesen werden, sowie Bioakkumulation in Süßwasserorganismen (Ahel et al. 1993, Ekelund et al. 1990). Die östrogene Aktivität von NP wurde in vitro und in vivo nachgewiesen. In vitro stimuliert NP die Vitellogenin-Genexpression in ForellenHepatozyten (Sumpter und Jobling 1995, White et al.1994) sowie das Wachstum der Östrogen-sensitiven Brustkrebszellen MCF-7 (Blom et al. 1998, Nagel et al.1997, White et al.1994). NP ist in der Lage, 17ß-Estradiol vom humanen und Fisch-Östrogenrezeptor zu verdrängen (Soto et al.1995, Jobling et al. 1995). Im in-vivo-Uterotrophic Assay in der ovarektomierten (ovx) Ratte induziert die Gabe von $100 \mathrm{mg} / \mathrm{Kg} / \mathrm{d}$ NP eine signifikante Erhöhung des Uterus-Gewichts. Watanabe et al. zeigten bei der Maus mit der DNAMicroarray-Analyse, dass im Uterus Gene, die von hoher Dosis $(50 \mathrm{mg} / \mathrm{Kg} / \mathrm{d})$ NP aktiviert werden, ebenfalls von 17 $\beta$-Estradiol aktiviert werden (Watanabe et al. 2004).

In vitro bindet NP humanen rekombinanten ER $\beta$ (Han et al. 2002). 


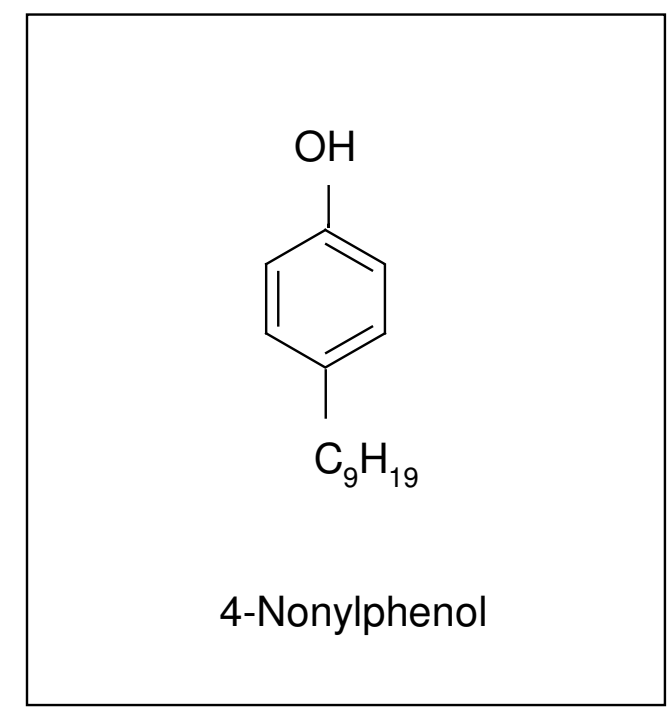

Abbildung 3: Strukturformel NP

\subsubsection{Phytoöstrogene}

Phytoöstrogene sind definiert als pflanzliche Komponenten, welche strukturell und funktionell Östrogenen und deren aktiven Metaboliten ähneln. Die beiden Hauptklassen der Phytoöstrogene sind Lignane und Isoflavone. Isoflavone finden sich in Hülsenfrüchten, insbesondere in Sojabohnen (Whitten und Patisaul 2001).

Vertreter der Isoflavone sind Genistein und Daidzein, sie besitzen die Fähigkeit, an Östrogenrezeptoren zu binden (Kuiper et al. 1998). In höheren Konzentrationen bindet Genistein den ER $\beta$ ähnlich stark wie 17ß-Estradiol (Morito et al. 2001). Coumestrol ist das bekannteste Coumestan unter den Isoflavonen mit dem höchsten östrogenen Potenzial (Kuiper et al. 1997).

Verschiedene Studien lassen vermuten, dass insbesondere die in der Sojabohne enthaltenen Isoflavone den postmenopausalen Knochenabbau verringern (Somekawa et al. 2001, Alekel et al. 2000, Potter et al. 1998). 


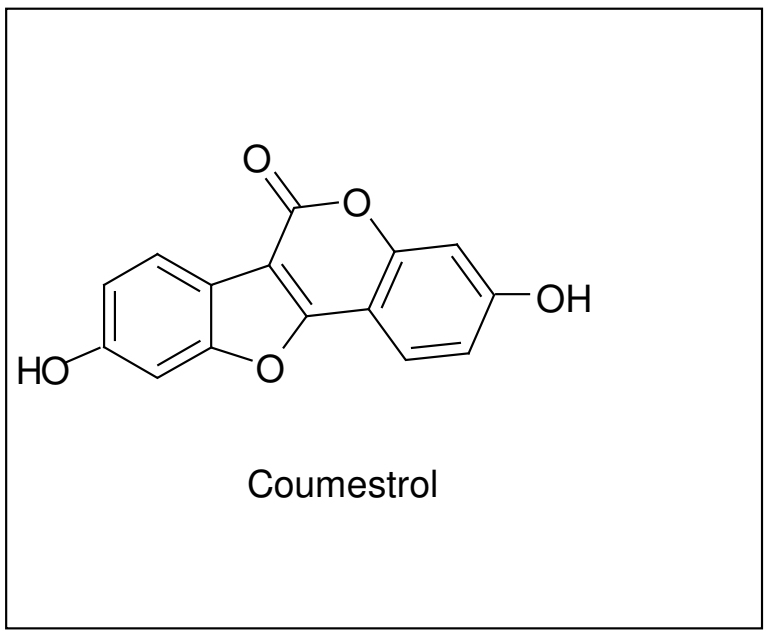

Abbildung 4: Strukturformel Coumestrol
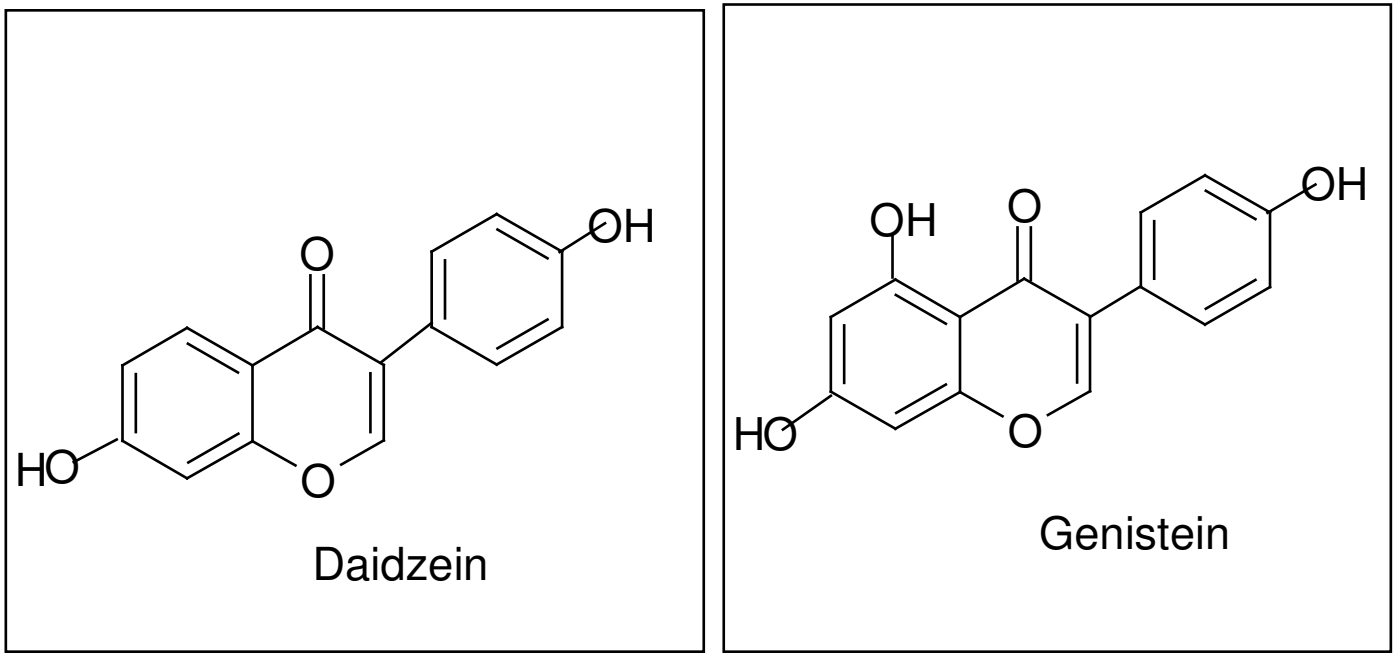

Abbildung 5: Strukturformel Daidzein

Abbildung 6: Strukturformel Genistein 


\subsection{Osteoporose}

Ein reguliertes und abgestimmtes System aus durch Osteoblasten-vermittelter Knochenformation und Osteoklasten-vermittelter Knochenresorption stellt sicher, dass die physiologische Knochenstruktur aufrechterhalten wird (Bland 2000). Ein Verlust dieses Gleichgewichtes führt zu einem Abfall der Knochenmasse. Osteoporose ist eine systemische Skeletterkrankung mit einer niedrigen Knochenmasse, pathologischer Mikroarchitektur des Knochengewebes und daraus resultierend einer erhöhten Knochenbrüchigkeit (Bartl und Bartl 2004).

\subsubsection{Definition der Osteoporose und der Osteopenie}

Nach der Leitlinie (DVO-Leitlinie 2009, Seite 1) des Dachverbands Osteologie e.V. ergibt sich folgende Definition: "Die Osteoporose ist eine systemische Skeletterkrankung, die durch eine mikroarchitektonische Verschlechterung des Knochengewebes charakterisiert ist, mit einem konsekutiven Anstieg der Knochenfragilität und der Neigung zu Frakturen. Sind bereits eine oder mehrere Frakturen als Folge der Osteoporose aufgetreten, liegt eine manifeste Osteoporose vor".

Zur Osteoporosediagnostik beim Menschen stellt die Osteodensitometrie per Dual-EnergyX-Ray-Absorptiometrie (DXA) die Methode der Wahl dar. Der absolute Wert dieser Knochendichtemessung wird in Bezug zu einer Referenzpopulation gesetzt und in Standardabweichungen angegeben. Der Vergleich mit einem jungen Referenzkollektiv ergibt den sogenannten T-Score. Nach Definition der WHO gilt ein T-Score bis $-1,0$ als Normalbefund, zwischen -1 und $-2,5$ handelt es sich um eine Osteopenie, ab $-2,5$ liegt eine Osteoporose vor (Raisz 2005a, Fogelmann und Blake 2005).

\subsubsection{Osteoporose in der Postmenopause}

Östrogene spielen eine entscheidende Rolle bei der Entwicklung und Instandhaltung des Skelettsystems. Aufgrund der abnehmenden ovariellen Östrogensekretion beobachtet man bei Frauen in der Postmenopause oder nach Ovarektomie eine verstärkte Demineralisierung des Skelettsystems, was zur Osteoporose führen kann (Patlak 2001, Gallagher AC et al. 1996). Abfall der Östrogensekretion führt u.a. zu einer Zunahme der Sekretion von Interleukinen und anderen Zytokinen, die wiederum zu einer erhöhten 
Aktivierung von Osteoklasten führt (Sunyer et al. 1999, Pacifici 1996). Aus der erhöhten Knochenresorption folgt eine Abnahme der Knochenmasse, vor allem im spongiösen oder trabekulären Knochen. Aufgrund der größeren Oberfläche des spongiösen Knochens wird dieser sieben mal schneller umgebaut als der kortikale Knochen (Gallagher JC 2003). Das Frakturrisiko bei Osteoporose in der Postmenopause besteht daher insbesondere für die trabekulären Knochen des axialen Skeletts, wie Wirbelsäule, proximaler Oberschenkel, Rippen und Becken.

\subsubsection{Tiermodell für postmenopausale Osteoporose}

Durch Ovarektomie (Ovx) der Ratten wird die körpereigene Steroidhormonsynthese überwiegend unterbunden. Sowohl die ovx Ratte als auch Frauen in der Postmenopause zeigen nach Verlust der ovariellen Funktion gleiche Erscheinungen in Bezug auf den Knochenstoffwechsel. Die ovx Ratte ist ein etabliertes, weit verbreitetes Modell für postmenopausale Osteoporose (Chow et al. 1992, Wronski et al. 1988).

Daher kann das Tiermodell der ovx Ratte für Vergleichsstudien der postmenopausalen Frau herangezogen werden.

\subsection{4 Östrogenwirkung am Knochen speziell in der Postmenopause}

Östrogene regulieren durch Bindung an den Östrogenrezeptor eine Menge von Prozessen an verschiedenen Geweben, unter anderem am Skelettsystem (Mc Donnell und Norris 2002). Ein Mangel an Östrogenen verursacht Osteoporose.

Eines der wichtigsten natürlichen Östrogene ist 17ß-Estradiol. Studien zeigten, dass E2 die Osteoblasten-Proliferation sowohl stimulieren sowie hemmen kann (Bland 2000).

Postmenopausale Knochenveränderungen können durch Östrogensubstitution oder Gabe Selektiver Östrogenrezeptor-Modulatoren (SERM) verhindert werden (Beardsworth et al. 1999, Ornoy et al. 1994, Prestwood et al. 1994). Vom ER existieren zwei Subtypen, sowohl ERa als auch ER $\beta$ werden in Osteoblasten (Vidal et al. 1999, Onoe et al. 1997, Komm et al. 1988), Osteozyten (Braidman et al. 1995) und Osteoklasten (Pensler et al. 1990) exprimiert. Bei der adulten Ratte überwiegt am Knochen das Vorkommen von ERa gegenüber ERß (Onoe et al.1997). 
Vidal et al. zeigten durch einen Versuch mit Östrogenrezeptor-Knockout-Mäusen (ERKO), dass $E R \alpha$, nicht $E R \beta$, für die östrogene Wirkung am Knochen verantwortlich ist (Vidal et al. 2000).

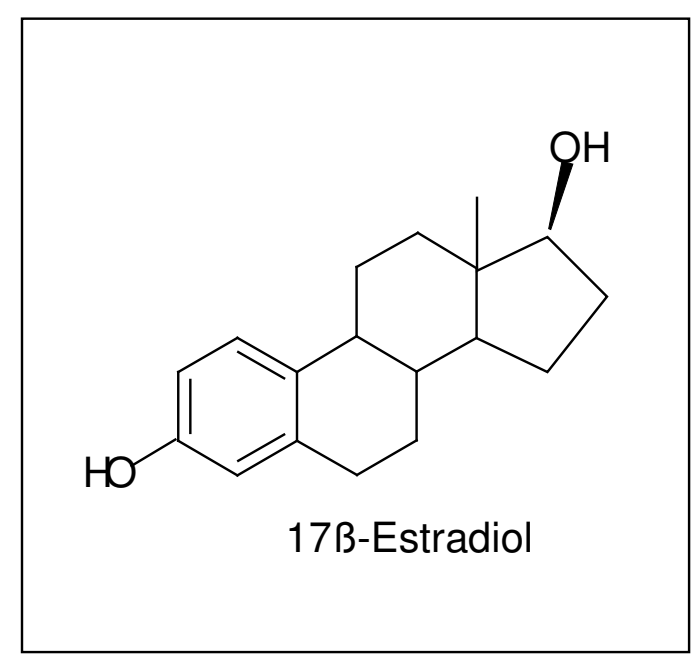

Abbildung 7: Strukturformel 17 $\beta$ - Estradiol 


\subsubsection{5 $\alpha$-Androstan-3 $\beta, 17 \beta$-diol (A-diol)}

Wie bereits erwähnt, liegen im Knochengewebe beide ER-Typen vor. 5a-Androstan$3 \beta, 17 \beta$-diol, welches aus Dihydrotestosteron metabolisiert werden kann, ist in der Lage, selektiv an ERß zu binden (Handa et al. 2008). Weihua et al. zeigten ebenfalls, dass Adiol ein ERß-Ligand ist und z.B. bei der männlichen Ratte auf das Prostatagewebe antiproliferativ wirkt (Weihua et al. 2002). A-diol scheint also ein natürlicher Bindungspartner an ERß zu sein und zeigt somit primär östrogene Effekte und keine androgenen Effekte (Pettersson et al. 2008).

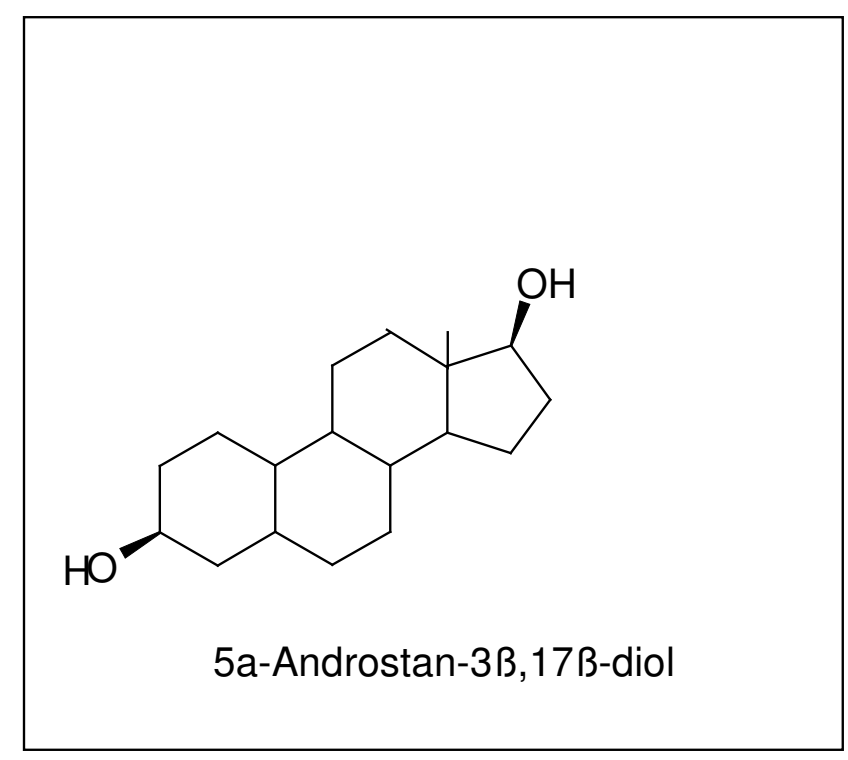

Abbildung 8: Strukturformel $5 \alpha$-Androstan-3 $\beta, 17 \beta$-diol 


\subsection{Ziele}

Unsere Untersuchung ist im Rahmen eines europäisch wissenschaftlichen Programms (EURISKED) durchgeführt worden. Bei diesem Projekt geht es um die multi-organische Risikoabschätzung von ausgewählten Endokrinen Disruptoren. In meiner Arbeit soll insbesondere die Wirkung auf den Knochen getestet werden und wie weit diese Wirkung der hier ausgewählten ED mit der von Östrogen vergleichbar ist.

Es ist wissenswert, inwieweit Frauen in der Postmenopause besonders durch ED belastet werden. Postmenopausale Osteoporose ist charakterisiert durch einen Abfall der Knochendichte und Knochenmasse (Peacock et al. 2002). Meine Arbeit soll zeigen, ob die ED 4-MBC, OMC, NP und Phytoöstrogene den postmenopausalen Knochenumbau zusätzlich beeinflussen und somit eine Bindung an den ER wahrscheinlich ist.

Lee et al. zeigten, dass ERa die östrogene Wirkung am Knochen vermittelt. Somit soll erörtert werden, ob eine Bindung von Endokrinen Disruptoren an diesen ER wahrscheinlich ist (Lee et al. 2003). Zum Vergleich wird ebenfalls die Wirkung von E2 und A-diol getestet. Die Stoffe E2, A-diol, 4-MBC, OMC, NP sowie Phytoöstrogene werden weiblichen ovx Sprague-Dawley-Ratten per os durch Futtergabe appliziert. Die Untersuchungen des Knochens wurden vor und nach Ovarektomie mit Hilfe eines peripheren quantitativen Computertomographen (pQCT) der Firma Stratec durchgeführt. Viele Versuche mit dem pQCT zeigten, dass die proximale Tibiametaphyse für diese Messungen an der Ratte besonders geeignet ist, da trabekulärer Knochen und Knochenumbau an dieser Stelle vorhanden sind (Frost und Jee 1992). Die Tibiametaphyse wird senkrecht belastet und erlangt die meiste Strukturstärke aus einem System sich überkreuzender Trabekel, welche die senkrechten Elemente unterstützen und seitliche Biegung und Reißen nach vertikaler Belastung begrenzen (Eastell 2003). Trennung dieser Trabekelverbindung tritt vorzugsweise bei postmenopausalen Frauen auf. Weiterhin soll getestet werden, inwieweit die oral applizierten ED ähnliche Wirkung auf die zu messenden Knochenparameter haben wie 17ß-Estradiol. Es soll überprüft werden, ob die Applikation von A-diol eine Wirkung auf den Knochen zeigt. Ob sojahaltige Ernährung mit den darin enthaltenen Isoflavonen Daidzein, Genistein und Coumestrol den Knochendichteverlust nach Ovarektomie verhindert oder verringert, soll zusätzlich untersucht werden. Durch die Messung mit dem pQCT ist es möglich festzustellen, ob sich der spongiöse Knochen schneller umbaut als der kortikale Knochen (Ferretti et al. 1996). 


\section{Material und Methoden}

\subsection{Tierversuche}

\subsubsection{Versuchstiere}

Die Versuche wurden mit 151 selbstgezüchteten weiblichen Sprague-Dawley-Ratten der 3.Generation, Aufzucht mit sojafreiem Futter, durchgeführt. Zu Beginn des Versuches waren die Ratten etwa 3 Monate alt. Das durchschnittliche Körpergewicht der Tiere betrug bei Ankunft 243,5 g. In einem Käfig wurden 5 - 6 Tiere gehalten, Belichtung dieser Käfige erfolgte von 6.00-18.00 Uhr bei einer Raumtemperatur von $23^{\circ} \mathrm{C}$. Die Tiere erhielten unterschiedlich zusammengesetztes Pellet-Futter, durch das die zu untersuchenden Stoffe appliziert wurden, und Wasser zur freien Verfügung. Die durchgeführten Tierversuche standen unter der Aufsicht von Frau PD Dr. med. Dana Seidlová-Wuttke, es lag eine Genehmigung der Bezirksregierung Braunschweig vor (Aktenzeichen 509.42502/0113.00).

\subsubsection{Ovarektomie der Ratten}

Die Ovarektomie (Ovx) erfolgte im Alter von 3 Monaten in intraperitonealer Narkose mit Xylazin (Rompun Fa. Bayer, Leverkusen) und Ketamin (Ketavet, Pharmacia\&Uplohn) 2,5mg/Tier, entspr. 45Mg/kg KGW im Verhältnis 4:5. Durch diese Applikation wurde eine Narkose über etwa eine Stunde erreicht. Für die Hautinzision am lateralen Abdomen wurden den Tieren per Rasur die Haare entfernt, Muskulatur und Peritoneum schichtweise durchtrennt um das Abdomen zu eröffnen. Nun präparierten wir Ovar und Uterus. Nach Darstellung erfolgte das Fassen des Ovars mit einer Pean-Klemme, die Unterbindung und Entfernung. Nach Kontrolle auf Blutungsfreiheit wurde der Uterus ins Cavum abdominis rückverlagert. Es folgte ein Nahtverschluss von Peritoneum und Muskulatur durch eine gemeinsame Naht mit Catgut, 3 metric ( Fa. Ethicon, Norderstedt). Die Haut wurde letztlich mit Michel-Klammern (Fa. Martin, Tuttlingen) verschlossen. 


\subsubsection{Applikation der zu untersuchenden Wirkstoffe}

Das verabreichte Futter in Pelletform wurde auf sojafreier und sojahaltiger Basis von der Firma ssniff (Spezialdiäten GmbH in Soest) hergestellt.

Die Tiere wurden in insgesamt 14 Gruppen eingeteilt, wobei Gruppe $1-11$ aus jeweils 11 Ratten und Gruppe 12 - 14 aus jeweils 10 Ratten bestanden. Die Gabe der zu untersuchenden Substanzen erfolgte insgesamt über 12 Wochen per os, beginnend an dem Tag der Ovx.

(A)

Die ersten 9 Versuchsgruppen erhielten jeweils sojafreies Futter mit folgender Menge Substanz pro Versuchstier täglich.

\begin{tabular}{|c|c|c|c|}
\hline Gruppe & Name & Substanz & Menge pro Tier $(\mathrm{mg} / \mathrm{d})$ \\
\hline 1 & NP low & 4-Nonylphenol & $0,43 \mathrm{mg} / \mathrm{d}$ \\
\hline 2 & NP high & 4-Nonylphenol & $1,78 \mathrm{mg} / \mathrm{d}$ \\
\hline 3 & E2 & $17 \beta$-Estradiol & $0,61 \mathrm{mg} / \mathrm{d}$ \\
\hline 4 & Ovx & Sojafreies Futter V1355, ssniff & - \\
\hline 5 & A-diol & 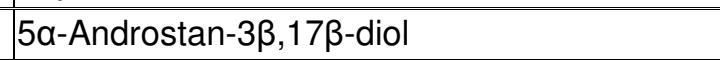 & $2,90 \mathrm{mg} / \mathrm{d}$ \\
\hline 6 & OMC low & Octyl-Methoxycinnamat (Eusolex 2292) & $52,48 \mathrm{mg} / \mathrm{d}$ \\
\hline 7 & OMC high & Octyl-Methoxycinnamat (Eusolex 2292) & $278,88 \mathrm{mg} / \mathrm{d}$ \\
\hline 8 & 4-MBC low & 4-Methylbenzyliden-Camphor (Eusolex 6300) & $59,28 \mathrm{mg} / \mathrm{d}$ \\
\hline 9 & 4-MBC high & 4-Methylbenzyliden-Camphor (Eusolex 6300) & $258,38 \mathrm{mg} / \mathrm{d}$ \\
\hline
\end{tabular}

Tabelle 1: Substanzzusatz im sojafreien Futter der Versuchsgruppen 1 - 9

(B)

Die Versuchsgruppen 10 - 14 erhielten sojahaltiges Futter mit folgender Menge Substanz pro Versuchstier täglich.

\begin{tabular}{|l|l|l|l|}
\hline Gruppe & Name & Substanz & Menge pro Tier (mg/d) \\
\hline $\mathbf{1 0}$ & Ovx soy & Sojahaltiges Futter ohne Substanzzusatz & \\
\hline $\mathbf{1 1}$ & NP high soy & 4-Nonylphenol & $1,88 \mathrm{mg} / \mathrm{d}$ \\
\hline $\mathbf{1 2}$ & OMC high soy & Octyl-Methoxycinnamat (Eusolex 2292) & $272 \mathrm{mg} / \mathrm{d}$ \\
\hline $\mathbf{1 3}$ & 4-MBC high soy & 4-Methylbenzyliden-Camphor (Eusolex 6300$)$ & $298,63 \mathrm{mg} / \mathrm{d}$ \\
\hline $\mathbf{1 4}$ & E2 soy & $17 \beta$-Estradiol & $0,58 \mathrm{mg} / \mathrm{d}$ \\
\hline
\end{tabular}

Tabelle 2: Substanzzusatz im Futter der Versuchsgruppen $10-14$ 
Aufgrund einer deutlichen Gewichtsabnahme der Tiere in den beiden 4-MBC-highGruppen im ersten Monat nach Substanzapplikation erfolgte eine Umstellung des Substanzzusatzes auf die 4-MBC low Menge.

\subsection{Quantitative Computertomographie}

Mit Hilfe der peripheren quantitativen Computertomographie ist es möglich, separat trabekuläre und kortikale Knochenparameter zu beurteilen (Ferretti 1999). Darüber hinaus kann die Dynamik der Osteoporoseentwicklung beurteilt werden. In diesem Versuch wurde das PQCT-System XCT Research SA, Stratec, Medizintechnik GmbH verwendet.

Als Zielregion wurde die proximale Metaphyse der linken Tibia $5 \mathrm{~mm}$ distal des Kniegelenks ausgewählt; dort können Knochendichte und Knochengeometrie in trabekulärem und spongiösem Knochen gemessen werden (Gasser 1995). Während der Messung wurden die zu untersuchenden Tiere mit Isoflurangas (Forene, Firma Abbott) narkotisiert. Es erfolgte die Fixierung des linken Beines in einer speziellen Halterung.

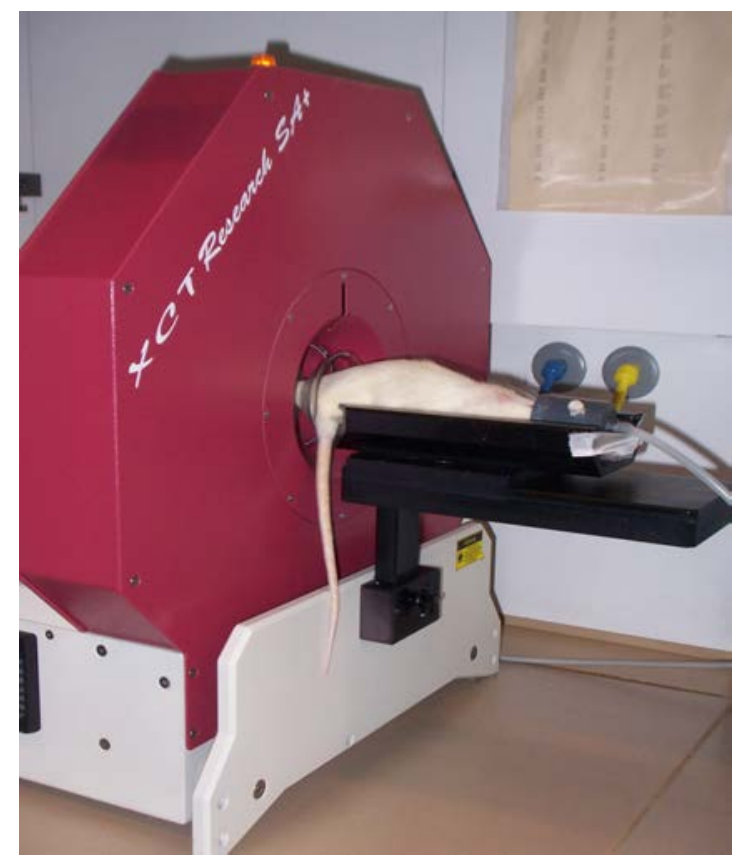

Abbildung 9: pQCT mit Tibiahalterung

(Abb. von PD Dr. med. Seidlová-Wuttke, Tierstall des Universitätsklinikums Göttingen) 


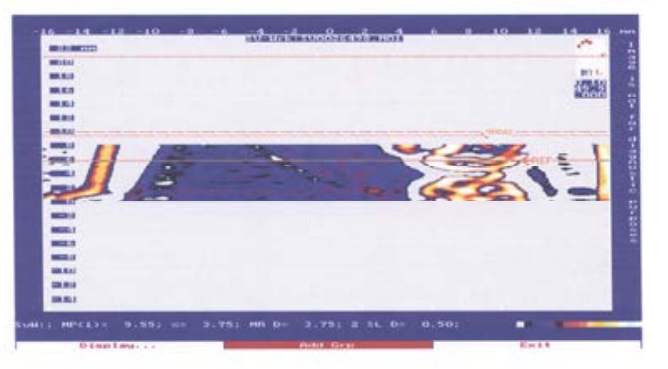

Abbildung 10: pQCT Scan, Referenzlinie Tibiametaphyse

Das PQCT-Gerät enthält eine Scanner-Einheit und ein analysierendes Computersystem. Die Scanner-Einheit besteht aus einer Strahlenquelle, die einen schmalen Röntgenstrahl emittiert, einem Detektor, welcher die Strahlenintensität und die Abschwächung durch das zu untersuchende Gewebe misst, und einem System, das radiale, transversale und axiale Bewegungen der Quelle und des Detektors erlaubt, um verschiedene Scanpositionen zu ermöglichen. Der Knochen wird mit oben genannter Halterung zwischen Strahlenquelle und Detektor positioniert. Zu Beginn der Messung wird per Computer ein Längsschnitt des zu untersuchenden Knochens erstellt, mit Hilfe einer Referenzlinie die geeignete Region der Tibiametaphyse eingestellt. Nachfolgend wird eine Serie von Querschnittsmessungen gestartet (15 mal in jeder Schnittebene, bei insgesamt 3 Ebenen). Die gescannten Bilder erscheinen während der Messung auf dem Bildschirm. Für trabekuläre Strukturen erfolgt die Messung 3,75mm und 4,25mm distal der Referenzlinie, für kortikale Parameter $15 \mathrm{~mm}$ distal der Referenzlinie. Ein gescanntes Areal wird in viele Bildpunkte (pixels) unterteilt. Diese Bildpunkte stellen Volumeneinheiten dar, welche als voxels bezeichnet werden. Die Anzahl der voxels pro Feld ist konstant (1024 x 1024).

Mit Hilfe der Softwareversion 5.2 (Stratec, Medizintechnik) wurde in jedem Querschnitt eine region of interest $(\mathrm{ROI})$ um die Tibia gezeichnet. Anschließend erfolgte die standardisierte Analyse in allen Schnittebenen. Die endgültige Auswertung der Ergebnisse erfolgte standardisiert durch das Loop Programm (Stratec, kompatibel mit Windows Excel). 
Durch Markierung der ROI ist es möglich anderes Gewebe, wie z.B. Fett, vom äußeren Rand des Knochens zu trennen (ContMode). Darüber hinaus sollen die trabekulären Bereiche von der kortikalen Hülle getrennt werden, um trabekuläre und kortikale sowie subkortikale Werte (PeelMode) zu erhalten. Während des Versuchs wurden eine Größe des Bildpunktes (Voxelsize) von $0,1 \mathrm{~mm}$ und ein Abschälmodus (Threshold) von 280 ausgewählt (ContMode 1, PeelMode 2, CortMode 1).

Die erste basale PQCT-Messung erfolgte an den intakten 3 Monate alten Tieren. Am Tag der Ovarektomie startete die Substanzapplikation per Futter für die nächsten 3 Monate. Nach diesen 3 Monaten führten wir die zweite pQCT-Messung durch. Nachfolgend wurden die Tiere getötet, Blut und diverse Organe konnten präpariert, eingefroren oder in Formaldehyd fixiert werden für weitere Untersuchungen.

\subsection{Statistische Auswertung}

Bei der Auswertung der Ergebnisse habe ich den Mittelwert und den Standardfehler des Mittelwertes (SEM) berechnet. Zur statistischen Auswertung wird das Softwareprogramm PRISM in den Versionen 3.0 und 5.0 verwendet. Es wird der unverbundene t-Test angewendet, das Signifikanzniveau wird auf $\mathrm{p}<0,05$ festgelegt.

Zum besseren Vergleich werden die Messwerte prozentrelativiert. Die Werte der Tiere vor Ovx der ersten pQCT-Messung werden gleich 100\% gesetzt.

Folgende Knochendichteparameter und Knochengeometrieparameter wurden gemessen und ausgewertet:

\begin{tabular}{|l|l|l|}
\hline Knochenparameter & Abkürzung & Einheit \\
\hline Spongiosadichte & TRAB DEN & $\mathrm{mg} / \mathrm{cm}^{3}$ \\
\hline Spongiosamasse & TRAB CNT & $\mathrm{mg}^{*}$ \\
\hline Endostale Fläche & TRAB A & $\mathrm{mm}^{2}$ \\
\hline Kortikalisdichte & CRT DEN & $\mathrm{mg} / \mathrm{cm}^{3}$ \\
\hline Kortikalismasse & CRT CNT & $\mathrm{mg}^{*}$ \\
\hline Fläche der Kortikalis & CRT A & $\mathrm{mm}^{2}$ \\
\hline
\end{tabular}

*der Wert bezieht sich auf die Mineralmasse einer Scheibe von $1 \mathrm{~mm}$ Dicke Tabelle 3: Ausgewählte Messparameter des Knochens 


\section{Ergebnisse}

\subsection{Futtermenge}

\subsubsection{Durchschnittlicher Tagesfutterverbrauch der Ratten unter 3- monatiger Applikation mit sojafreiem und sojahaltigem Futter von E2, A-diol, NP, 4-MBC und OMC}

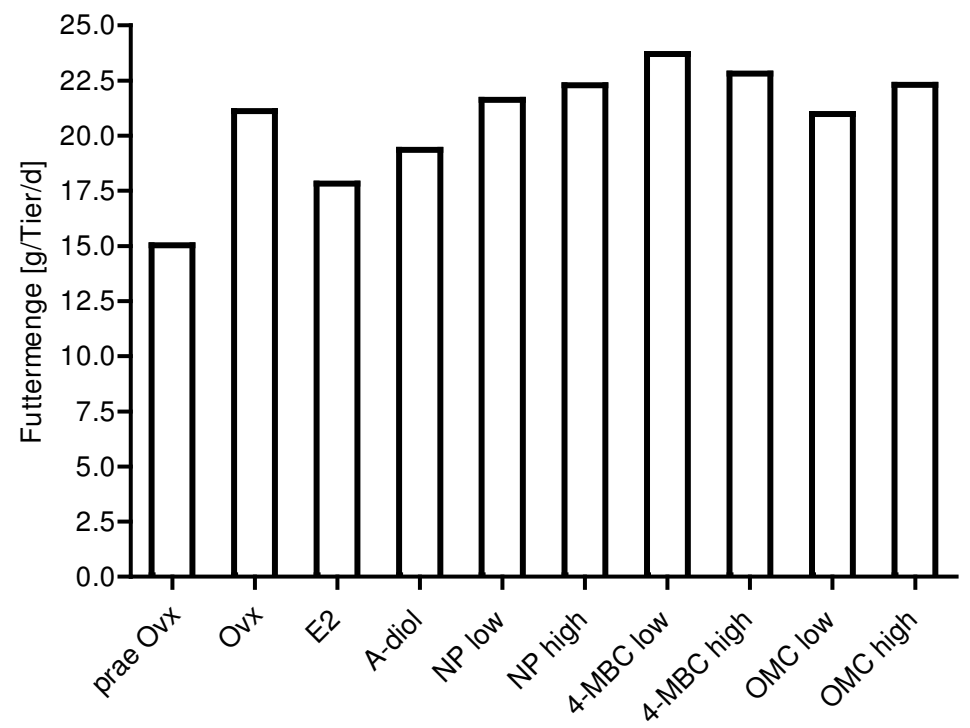

Abbildung 11: Futtermenge [g/Tier/d] unter 3-monatiger Applikation mit sojafreiem Futter von E2 (0,61mg/d), Adiol $(2,90 \mathrm{mg} / \mathrm{d})$, NP low $(0,43 \mathrm{mg} / \mathrm{d})$, NP high $(1,78 \mathrm{mg} / \mathrm{d}), 4-\mathrm{MBC}$ low $(59,28 \mathrm{mg} / \mathrm{d}), 4-\mathrm{MBC}$ high $(258,38 \mathrm{mg} / \mathrm{d})$, OMC low $(52,48 \mathrm{mg} / \mathrm{d})$ und OMC high $(278,88 \mathrm{mg} / \mathrm{d})$

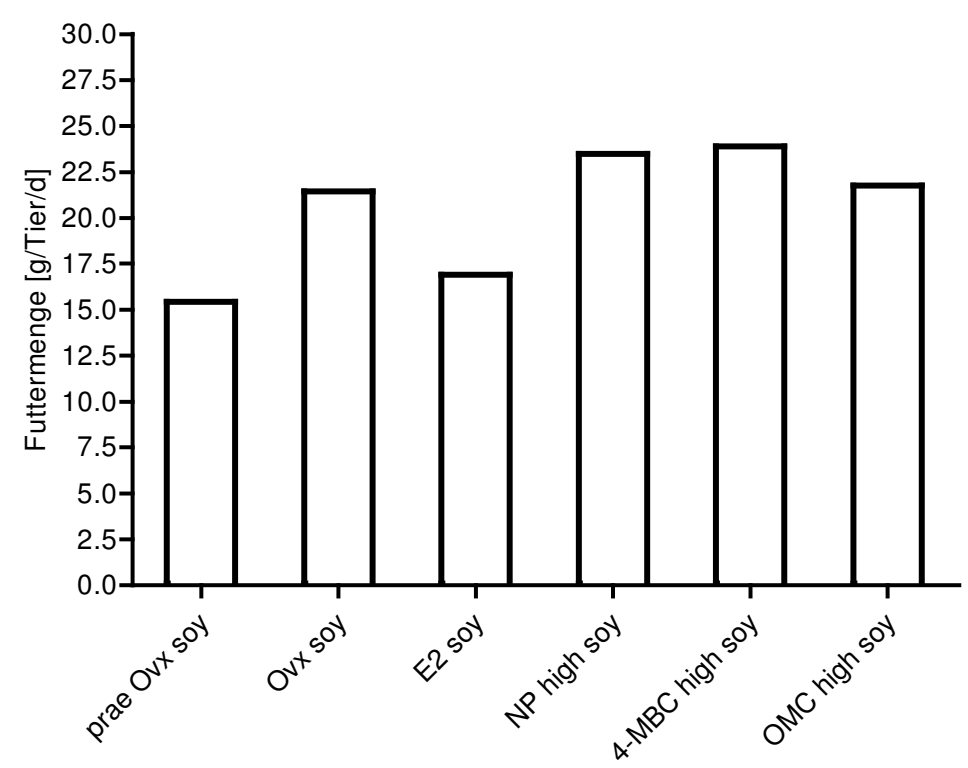

Abbildung 12: Futtermenge [g/Tier/d] unter 3-monatiger Applikation mit sojahaltigem Futter von E2 $(0,58 \mathrm{mg} / \mathrm{d})$, NP high $(1,88 \mathrm{mg} / \mathrm{d}), 4-\mathrm{MBC}$ high $(298,63 \mathrm{mg} / \mathrm{d})$ und OMC high $(272 \mathrm{mg} / \mathrm{d})$ 
Die Abbildungen 11 und 12 zeigen, dass nach Ovx der durchschnittliche Futterverbrauch bei allen Tieren zunimmt. Unter E2-Gabe zeigt sich im Vergleich zu den anderen Gruppen nach Ovx ein verhältnismäßig geringerer Futterverbrauch. Bezüglich der Gabe von sojahaltigem oder sojafreiem Futter zeigt sich kein Unterschied. 


\subsection{Körpergewicht}

\subsubsection{Effekte von E2, A-diol, NP, 4-MBC und OMC (3 Monate Applikation mit sojafreiem und sojahaltigem Futter) auf das durchschnittliche Körpergewicht der Ratten}

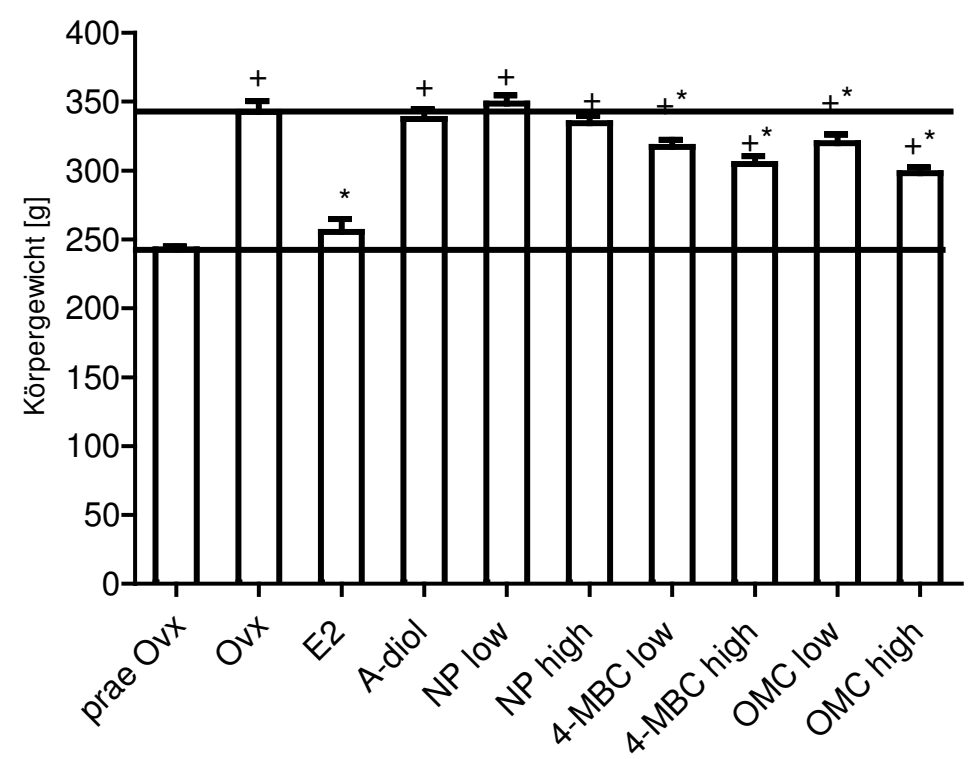

Abbildung 13: Körpergewicht [g] unter 3-monatiger Applikation mit sojafreiem Futter von E2 $(0,61 \mathrm{mg} / \mathrm{d})$, A-diol $(2,90 \mathrm{mg} / \mathrm{d})$, NP low $(0,43 \mathrm{mg} / \mathrm{d})$, NP high $(1,78 \mathrm{mg} / \mathrm{d})$, 4-MBC low $(59,28 \mathrm{mg} / \mathrm{d})$, 4-MBC high $(258,38 \mathrm{mg} / \mathrm{d})$, OMC low $(52,48 \mathrm{mg} / \mathrm{d})$ und OMC high $(278,88 \mathrm{mg} / \mathrm{d}),+p<0,05$ versus prae Ovx, ${ }^{*} p<0,05$ versus $O v x$

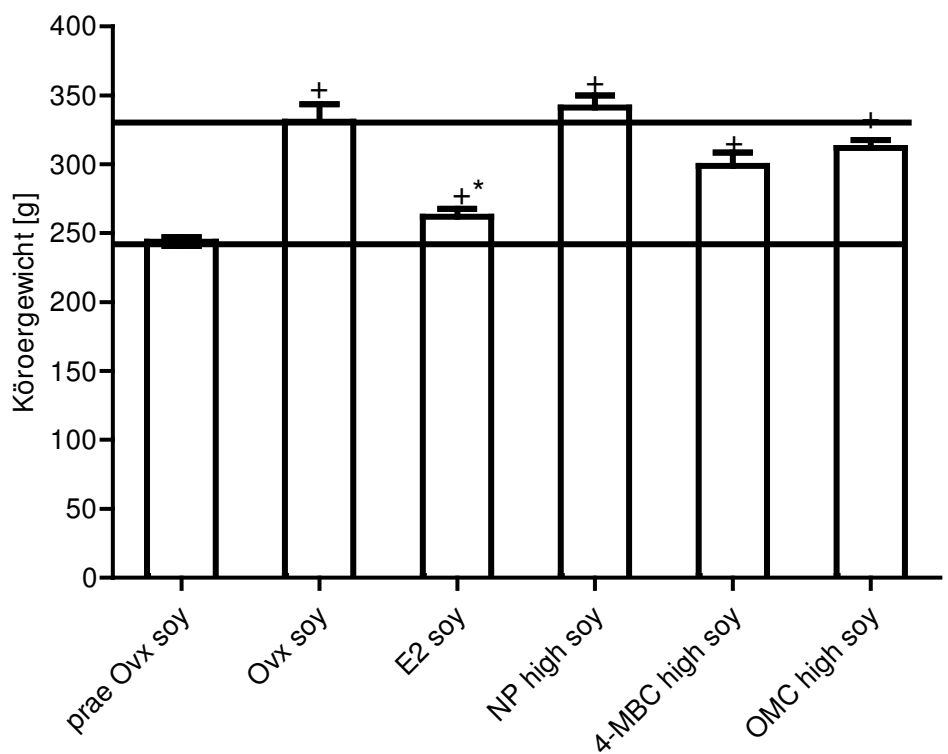

Abbildung 14: Körpergewicht [g] unter 3-monatiger Applikation mit sojahaltigem Futter von E2 $(0,58 \mathrm{mg} / \mathrm{d})$, NP high $(1,88 \mathrm{mg} / \mathrm{d}), 4-\mathrm{MBC}$ high $(298,63 \mathrm{mg} / \mathrm{d})$ und OMC high $(272 \mathrm{mg} / \mathrm{d})$, $+p<0,05$ versus prae Ovx soy, ${ }^{*} p<0,05$ versus Ovx soy 
Abbildung 13 zeigt, dass nach Ovx das durchschnittliche Körpergewicht der Tiere in fast allen Gruppen signifikant zunimmt. Nur in der E2-Gruppe ist die Zunahme des Körpergewichts deutlich geringer und daher nicht signifikant. Das Gewicht der Tiere der E2-, 4-MBC- und OMC- Gruppen ist signifikant geringer als in der Ovx-Gruppe.

Abbildung 14 bestätigt, dass E2-Gabe eine deutlich geringere Erhöhung des Körpergewichts nach Ovx bewirkt. Die zusätzliche Gabe von sojahaltigem Futter bewirkt keine Veränderung. 


\subsection{Knochendichtemessung in der Metaphyse der Tibia}

\subsubsection{Effekt von E2, A-diol, NP, 4-MBC und OMC (Applikation 3 Monate mit sojafreiem und sojahaltigem Futter) auf die metaphysäre Spongiosadichte der ovarektomierten Ratte}

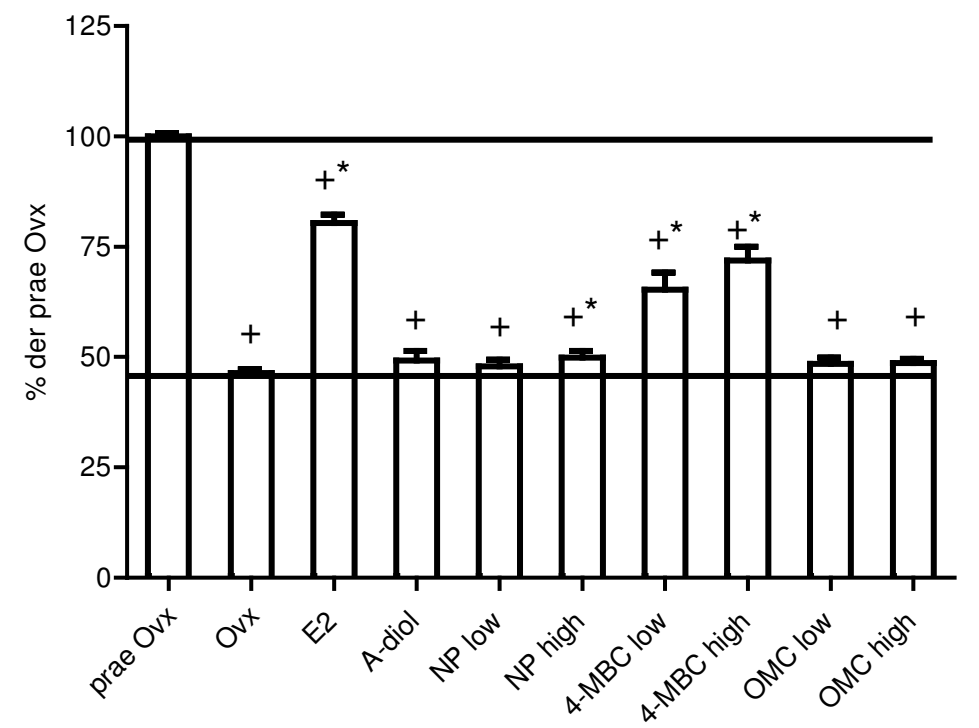

Abbildung 15: Spongiosadichte der Tibiametaphyse vor und nach 3-monatiger Applikation mit sojafreiem Futter von E2 $(0,61 \mathrm{mg} / \mathrm{d})$, A-diol $(2,90 \mathrm{mg} / \mathrm{d})$, NP low $(0,43 \mathrm{mg} / \mathrm{d})$, NP high $(1,78 \mathrm{mg} / \mathrm{d})$, 4MBC low $(59,28 \mathrm{mg} / \mathrm{d})$, 4-MBC high $(258,38 \mathrm{mg} / \mathrm{d})$, OMC low $(52,48 \mathrm{mg} / \mathrm{d})$ und OMC high $(278,88 \mathrm{mg} / \mathrm{d}),+p<0,05$ versus prae Ovx, ${ }^{*} p<0,05$ versus $O v x$

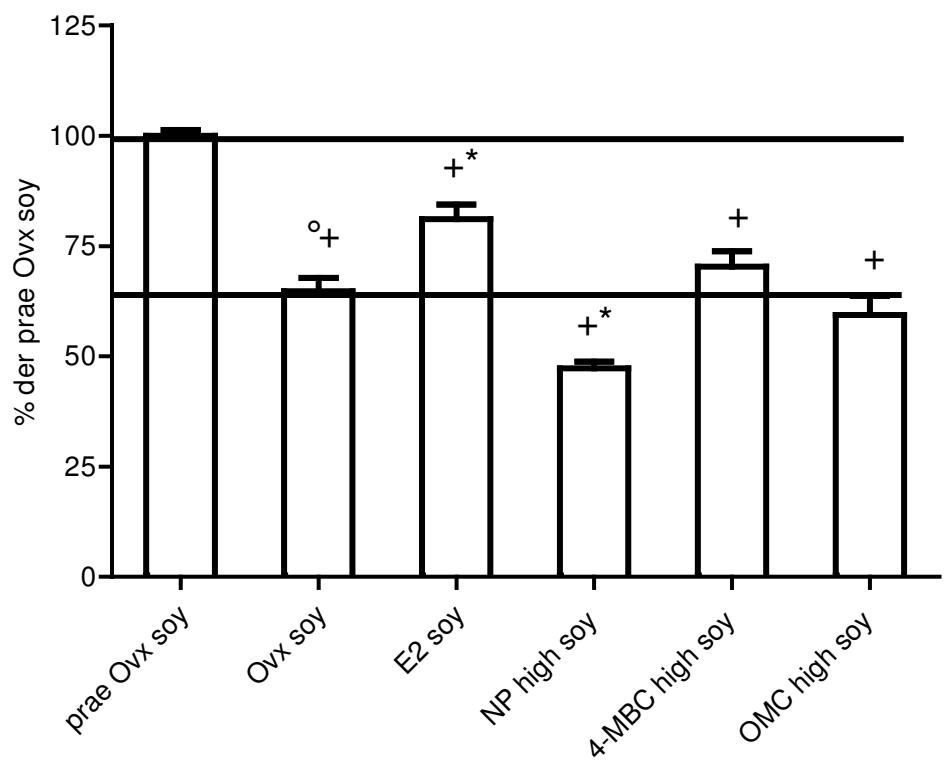

Abbildung 16: Spongiosadichte der Tibiametaphyse vor und nach 3-monatiger Applikation mit sojahaltigem Futter von E2 $(0,58 \mathrm{mg} / \mathrm{d})$, NP high $(1,88 \mathrm{mg} / \mathrm{d})$, 4-MBC high $(298,63 \mathrm{mg} / \mathrm{d})$ und OMC high $(272$ $\mathrm{mg} / \mathrm{d}),+\mathrm{p}<0,05$ versus prae Ovx soy, ${ }^{*} \mathrm{p}<0,05$ versus Ovx soy, ${ }^{\circ} \mathrm{p}<0,05$ versus Ovx 
In Abbildung 15 wird dargestellt, wie die Spongiosadichte nach Ovx bei allen Tieren signifikant abfällt. Im Vergleich zur Ovx-Gruppe ist dieser Abfall der Spongiosadichte bei den Tieren unter E2-, NP-high-, 4-MBC-low- und 4-MBC-high-Applikation signifikant geringer.

Abbildung 16 zeigt, dass unter Gabe von sojahaltigem Futter die Spongiosadichte ebenfalls in allen Gruppen nach Ovx signifikant abnimmt. In der E2-soy-Gruppe ist die Höhe dieser Abnahme signifikant geringer als in der Ovx-soy-Gruppe. Die Tiere der NPhigh-soy-Gruppe zeigen eine signifikant stärkere Abnahme der Spongiosadichte als die Ovx-soy-Tiere.

Im Vergleich von Abbildung 15 und 16 wird deutlich, dass die alleinige Gabe von sojahaltigem Futter bewirkt, dass die Spongiosadichte nach Ovx signifikant weniger abfällt als unter sojafreiem Futter. 


\subsubsection{Effekt von E2, A-diol, NP, 4-MBC und OMC (3 Monate Applikation mit sojafreiem und sojahaltigem Futter) auf die metaphysäre Kortikalisdichte der ovarektomierten Ratte}

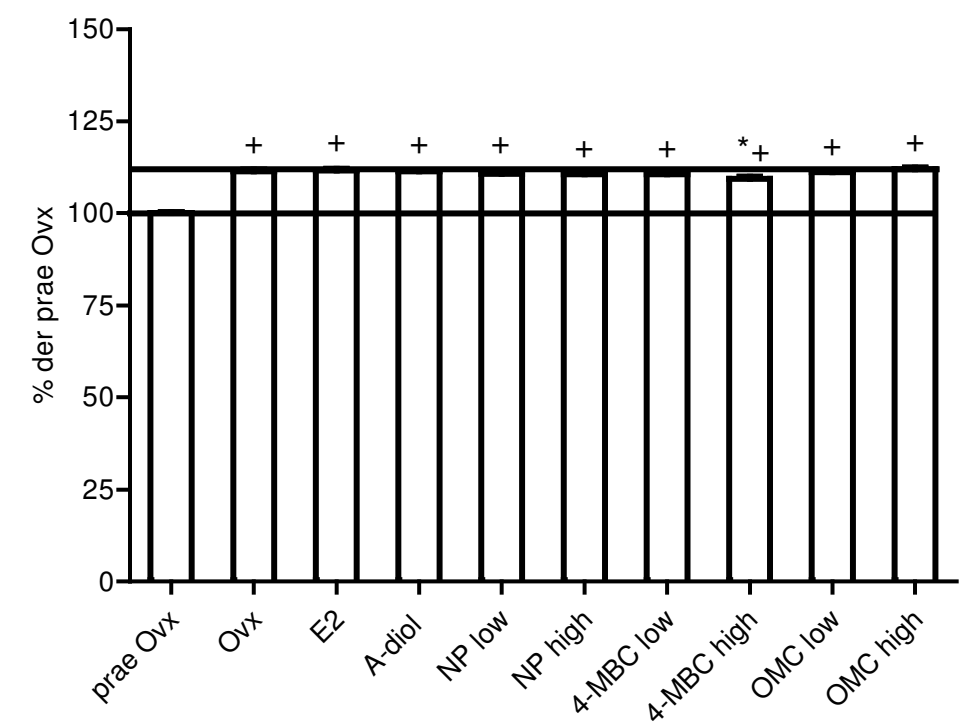

Abbildung 17: Kortikalisdichte der Tibiametaphyse vor und nach 3-monatiger Applikation mit sojafreiem Futter von E2 $(0,61 \mathrm{mg} / \mathrm{d})$, A-diol $(2,90 \mathrm{mg} / \mathrm{d})$, NP low $(0,43 \mathrm{mg} / \mathrm{d})$, NP high $(1,78 \mathrm{mg} / \mathrm{d})$, 4MBC low $(59,28 \mathrm{mg} / \mathrm{d}), 4-M B C$ high $(258,38 \mathrm{mg} / \mathrm{d})$, OMC low $(52,48 \mathrm{mg} / \mathrm{d})$ und OMC high $(278,88 \mathrm{mg} / \mathrm{d}),+p<0,05$ versus prae $O v x,{ }^{*} p<0,05$ versus $O v x$

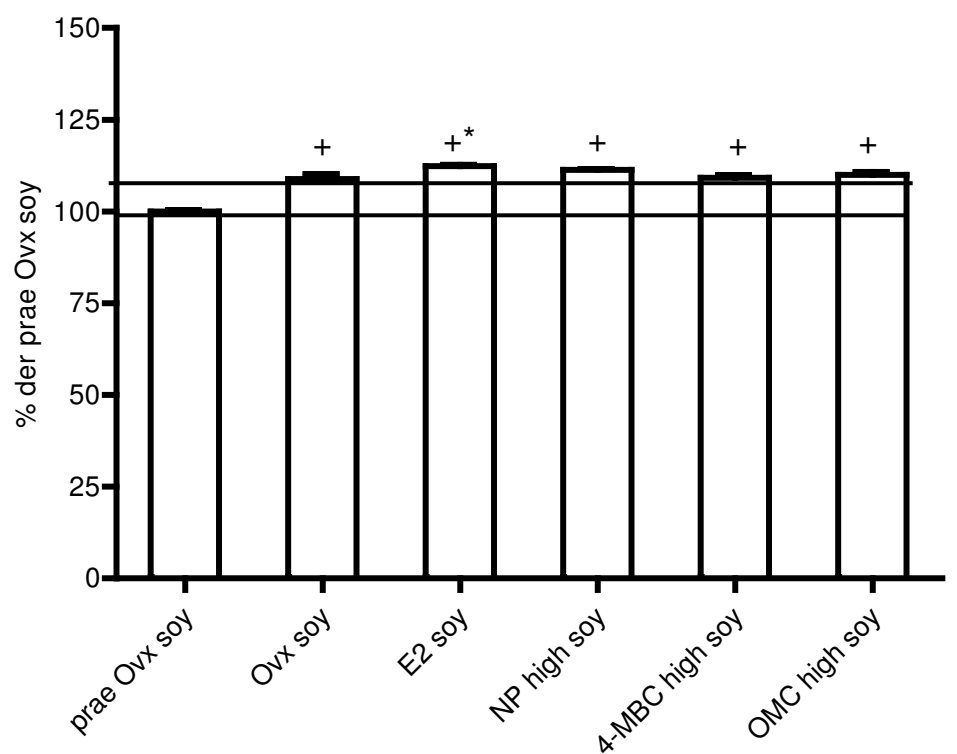

Abbildung 18: Kortikalisdichte der Tibiametaphyse vor und nach 3-monatiger Applikation mit sojahaltigem Futter von E2 (0,58mg/d), NP high (1,88mg/d), 4-MBC high $(298,63 \mathrm{mg} / \mathrm{d})$ und OMC high $(272$ $\mathrm{mg} / \mathrm{d}),+p<0,05$ versus prae Ovx soy, ${ }^{*} p<0,05$ versus Ovx soy 
In den Abbildungen 17 und 18 nimmt die Kortikalisdichte nach Ovx bei allen Tieren signifikant zu. Die 4-MBC-high-Gruppe aus Abbildung 17 zeigt einen signifikant geringeren Anstieg der Kortikalisdichte nach Ovx.

In der E2-soy-Gruppe in Abbildung 18 zeigt sich eine signifikant deutlichere Erhöhung der Kortikalisdichte nach Ovx. 


\subsection{Ergebnisse der Knochenmassemessungen in der Tibiametaphyse}

\subsubsection{Effekt von E2, A-diol, NP, 4-MBC und OMC (3 Monate Applikation mit sojafreiem und sojahaltigem Futter) auf die Spongiosamasse der Metaphyse der ovarektomierten Ratte}

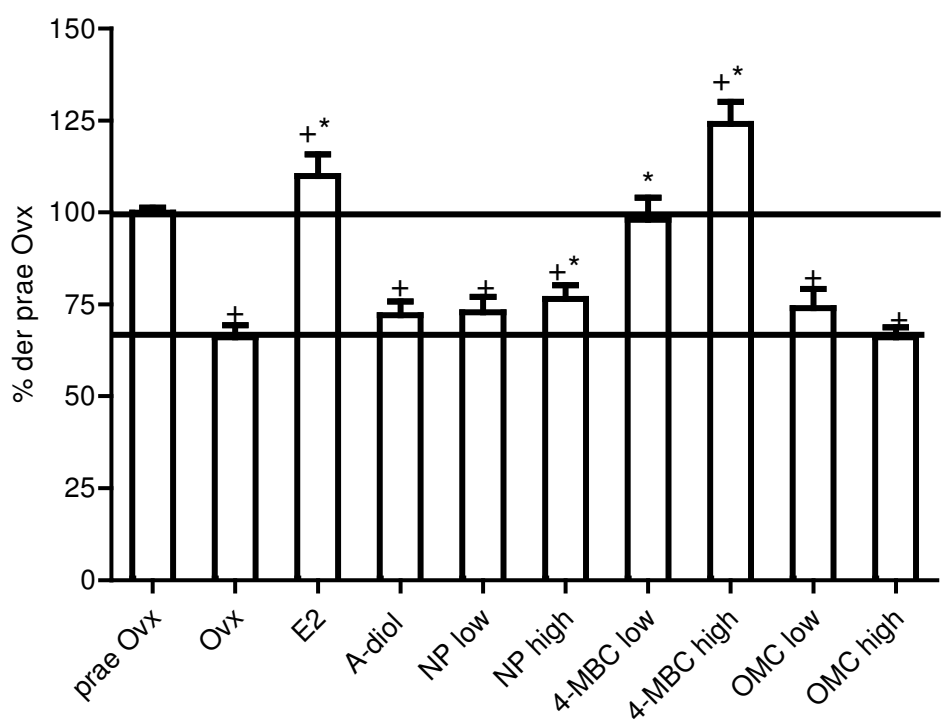

Abbildung 19: Spongiosamasse der Tibiametaphyse vor und nach 3-monatiger Applikation mit sojafreiem Futter von E2 $(0,61 \mathrm{mg} / \mathrm{d})$, A-diol $(2,90 \mathrm{mg} / \mathrm{d})$, NP low $(0,43 \mathrm{mg} / \mathrm{d})$, NP high $(1,78 \mathrm{mg} / \mathrm{d})$, 4MBC low $(59,28 \mathrm{mg} / \mathrm{d})$, 4-MBC high $(258,38 \mathrm{mg} / \mathrm{d})$, OMC low $(52,48 \mathrm{mg} / \mathrm{d})$ und OMC high $(278,88 \mathrm{mg} / \mathrm{d}),+p<0,05$ versus prae Ovx, ${ }^{*} p<0,05$ versus Ovx

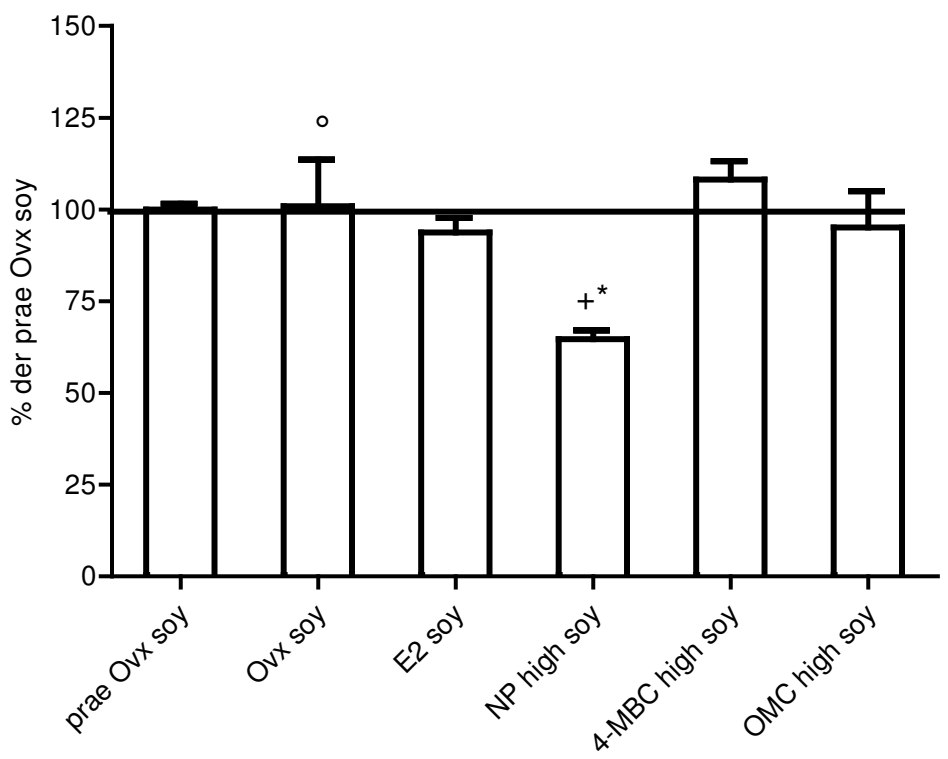

Abbildung 20: Spongiosamasse der Tibiametaphyse vor und nach 3-monatiger Applikation mit sojahaltigem Futter von E2 (0,58mg/d), NP high $(1,88 \mathrm{mg} / \mathrm{d})$, 4-MBC high $(298,63 \mathrm{mg} / \mathrm{d})$ und OMC high $(272$ $\mathrm{mg} / \mathrm{d}),+p<0,05$ versus prae Ovx soy, ${ }^{*} p<0,05$ versus Ovx soy, ${ }^{\circ} p<0,05$ versus Ovx 
Abbildung 19 zeigt, dass die Spongiosamasse der Tiere durch Ovx abnimmt. Bei den Tieren der E2- und 4-MBC-high-Gruppen nimmt die Spongiasamasse nach Ovx zu und ist damit wie bei den Tieren der NP-high- und 4-MBC-low-Gruppen signifikant höher als in der Ovx-Gruppe.

In Abbildung 20 ist sichtbar, dass die alleinige Gabe von sojahaltigem Futter einen Abfall der Spongiosamasse verhindert, dieses Ergebnis ist signifikant gegenüber den ovx Tieren. Bei den Tieren der 4-MBC-high-soy-Gruppe nimmt die Spongiosamasse nach Ovx sogar zu. In der E2-soy-Gruppe nimmt die Spongiosamasse nach Ovx leicht ab. Die Tiere der NP-high-soy-Gruppe zeigen im Vergleich zu den anderen Gruppen der Abbildung 20 einen signifikant stärkeren Abfall der Spongiosamasse. 


\subsubsection{Effekt von E2, A-diol, NP, 4-MBC und OMC (3 Monate Applikation mit sojafreiem und sojahaltigem Futter) auf die Kortikalismasse der Metaphyse}

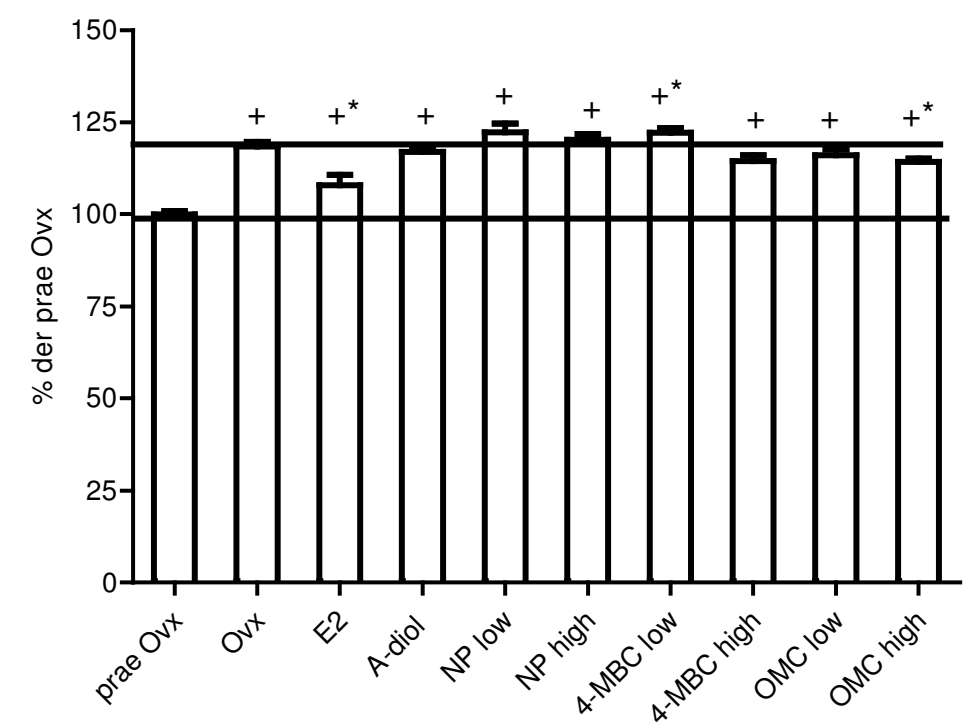

Abbildung 21: Kortikalismasse der Tibiametaphyse vor und nach 3-monatiger Applikation mit sojafreiem Futter von E2 (0,61 mg/d), A-diol $(2,90 \mathrm{mg} / \mathrm{d})$, NP low $(0,43 \mathrm{mg} / \mathrm{d})$, NP high $(1,78 \mathrm{mg} / \mathrm{d}), 4-$ MBC low $(59,28 \mathrm{mg} / \mathrm{d})$, 4-MBC high $(258,38 \mathrm{mg} / \mathrm{d})$, OMC low $(52,48 \mathrm{mg} / \mathrm{d})$ und OMC high $(278,88 \mathrm{mg} / \mathrm{d}),+p<0,05$ versus prae Ovx, ${ }^{*} p<0,05$ versus Ovx

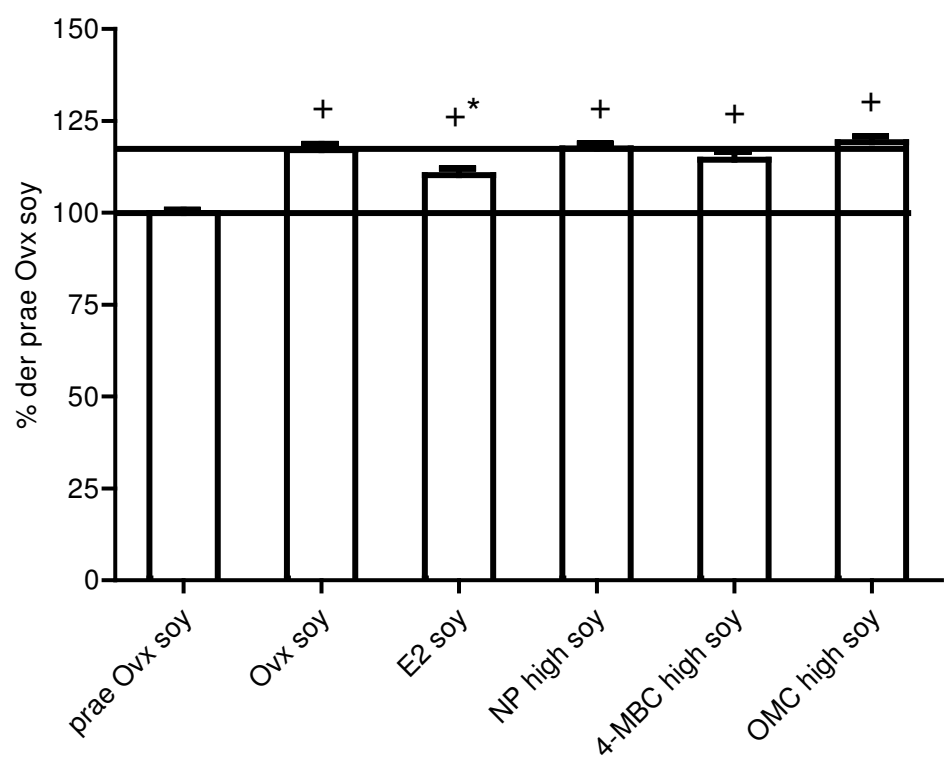

Abbildung 22: Kortikalismasse der Tibiametaphyse vor und nach 3-monatiger Applikation mit sojahaltigem Futter, von E2 $(0,58 \mathrm{mg} / \mathrm{d})$, NP high $(1,88 \mathrm{mg} / \mathrm{d}), 4-M B C$ high $(298,63 \mathrm{mg} / \mathrm{d})$ und OMC high $(272$ $\mathrm{mg} / \mathrm{d}),+p<0,05$ versus prae Ovx soy, ${ }^{*} p<0,05$ versus Ovx soy 
In den Abbildungen 21 und 22 wird deutlich, dass die Kortikalismasse bei allen Tieren nach Ovx zunimmt. Bei den sojafreien Tieren aus Abbildung 21 nimmt die Kortikalismasse nach Ovx in der E2- und OMC-high-Gruppe signifikant geringer zu, als in der Ovx-Gruppe. Abbildung 24 zeigt, dass bei den E2-soy-Tieren die Kortikalismasse signifikant geringer ansteigt als in der Ovx-Gruppe. 


\subsection{Ergebnisse der Messung der endostalen Fläche in der Metaphyse der Tibia}

\subsubsection{Effekt von E2, A-diol, NP, 4-MBC und OMC (3 Monate Applikation mit sojafreiem und sojahaltigem Futter) auf die endostale Fläche der Tibiametaphyse}

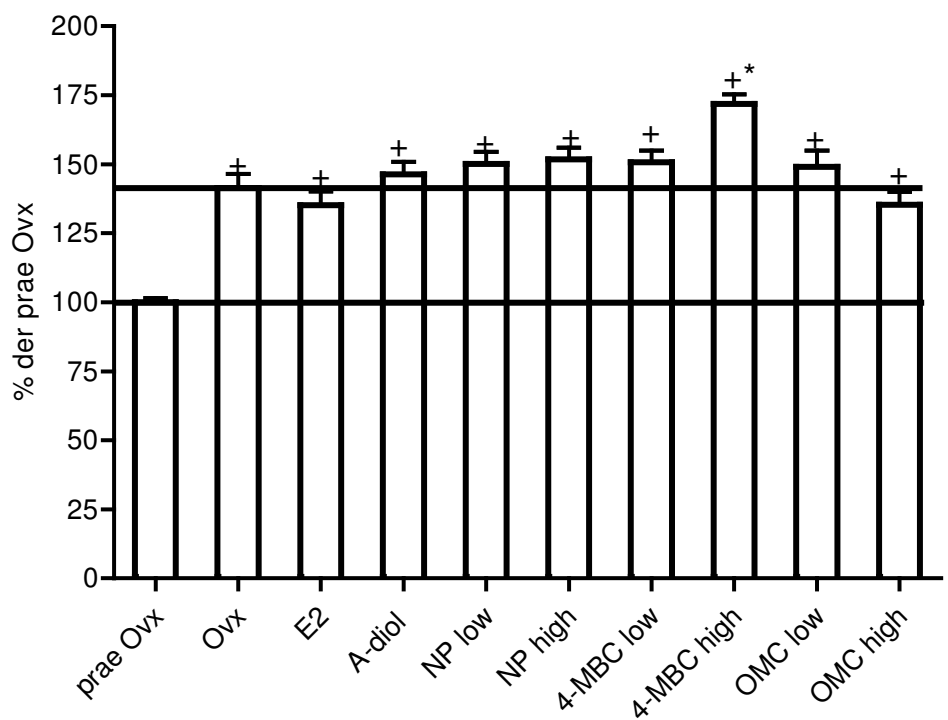

Abbildung 23: Endostale Fläche der Tibiametaphyse vor und nach 3-monatiger Applikation mit sojafreiem Futter von E2 $(0,61 \mathrm{mg} / \mathrm{d})$, A-diol $(2,90 \mathrm{mg} / \mathrm{d})$, NP low $(0,43 \mathrm{mg} / \mathrm{d})$, NP high $(1,78 \mathrm{mg} / \mathrm{d}), 4$ MBC low $(59,28 \mathrm{mg} / \mathrm{d})$, 4-MBC high $(258,38 \mathrm{mg} / \mathrm{d})$, OMC low $(52,48 \mathrm{mg} / \mathrm{d})$ und OMC high $(278,88 \mathrm{mg} / \mathrm{d}),+p<0,05$ versus prae Ovx, ${ }^{*} p<0,05$ versus Ovx

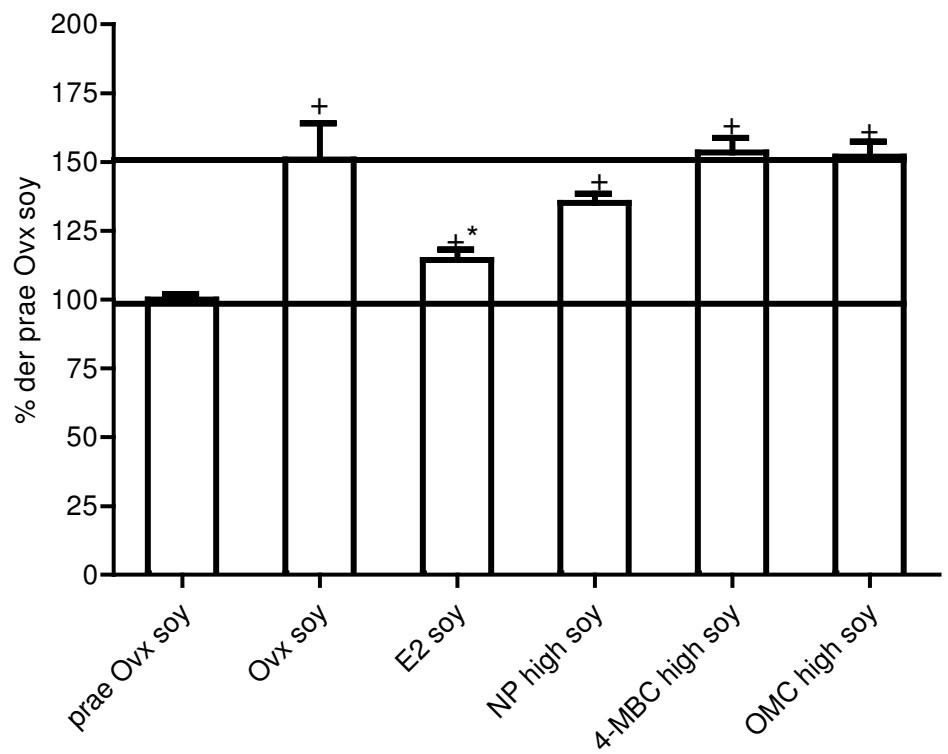

Abbildung 24: Endostale Fläche der Tibiametaphyse vor und nach 3-monatiger Applikation mit sojahaltigem Futter, von E2 (0,58mg/d), NP high (1,88mg/d), 4-MBC high $(298,63 \mathrm{mg} / \mathrm{d})$ und OMC high $(272$ $m g / d),+p<0,05$ versus prae Ovx soy, ${ }^{*} p<0,05$ versus Ovx soy 
Die Abbildungen 23 und 24 lassen erkennen, dass die endostale Fläche bei allen Tieren nach Ovx signifikant zunimmt. In der 4-MBC-high-Gruppe ist die endostale Fläche signifikant höher als in der Ovx-Gruppe.

Bei den Tieren der E2-soy-Gruppe in Abbildung 24 ist die Zunahme der endostalen Fläche signifikant geringer als bei den Tieren der Ovx-soy-Gruppe. 


\subsubsection{Effekt von E2, A-diol, NP, 4-MBC und OMC (3 Monate Applikation mit sojafreiem und sojahaltigem Futter) auf die Fläche der Kortikalis der Metaphyse der ovarektomierten Ratte}

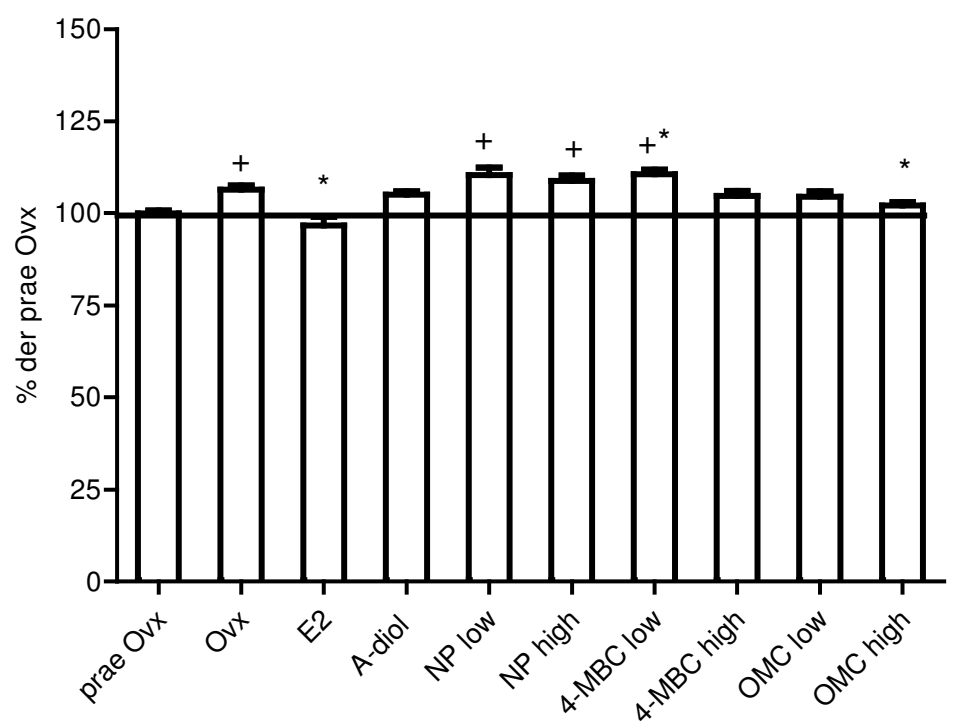

Abbildung 25: Fläche der Kortikalis der Tibiametaphyse vor und nach 3-monatiger Applikation mit sojafreiem Futter von E2 $(0,61 \mathrm{mg} / \mathrm{d})$, A-diol $(2,90 \mathrm{mg} / \mathrm{d})$, NP low $(0,43 \mathrm{mg} / \mathrm{d})$, NP high $(1,78 \mathrm{mg} / \mathrm{d}), 4-\mathrm{MBC}$ low $(59,28 \mathrm{mg} / \mathrm{d})$, 4-MBC high $(258,38 \mathrm{mg} / \mathrm{d})$, OMC low $(52,48 \mathrm{mg} / \mathrm{d})$ und OMC high $(278,88 \mathrm{mg} / \mathrm{d}),+p<0,05$ versus prae $O v x,{ }^{*} p<0,05$ versus $O v x$

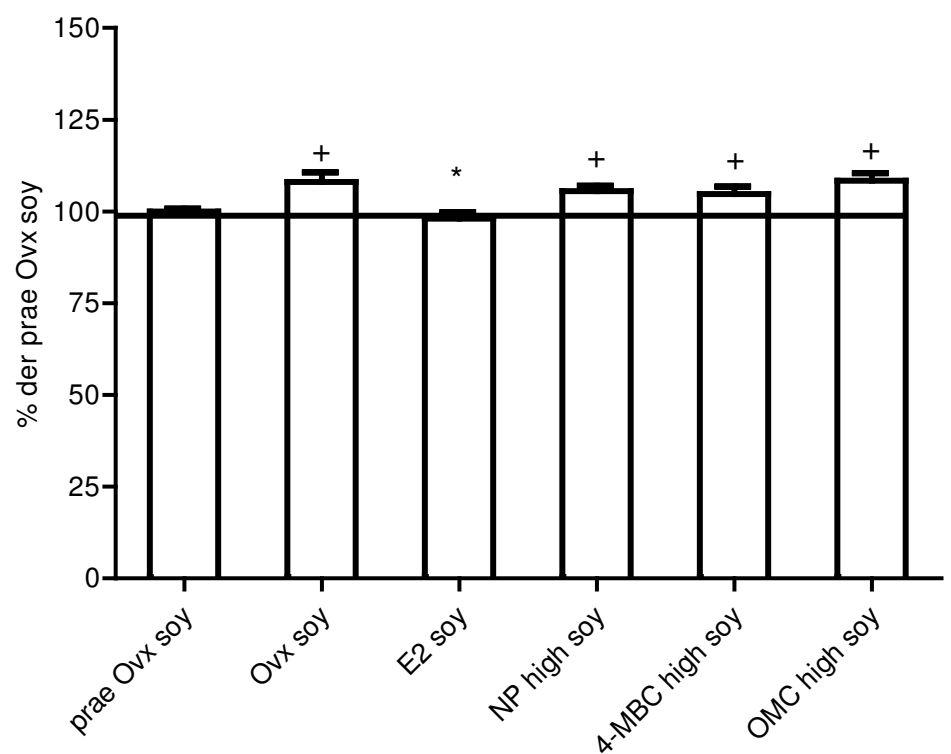

Abbildung 26:Fläche der Kortikalis der Tibiametaphyse vor und nach 3-monatiger Applikation mit sojahaltigem Futter von E2 $(0,58 \mathrm{mg} / \mathrm{d})$, NP high $(1,88 \mathrm{mg} / \mathrm{d}), 4-\mathrm{MBC}$ high $(298,63 \mathrm{mg} / \mathrm{d})$ und OMC high $(272 \mathrm{mg} / \mathrm{d}),+p<0,05$ versus prae Ovx soy, ${ }^{*} p<0,05$ versus Ovx soy 
Abbildung 25 macht deutlich, dass die Kortikalisfläche nach Ovx zunimmt. Unter E2Applikation zeigt sich eine Abnahme der Kortikalisfläche, diese ist hier signifikant geringer als in der Ovx-Gruppe. Die Tiere der OMC-high-Gruppe weisen ebenfalls eine signifikant geringere Kortikalisfläche auf als die ovx Tiere.

Bei den sojahaltigen Gruppen der Abbildung 26 zeigt sich nach Ovx in der E2-soy-Gruppe eine signifikant geringere Kortikalisfläche als bei den ovx Tieren. 


\section{Diskussion}

\subsection{Ziele}

In meiner Arbeit steht die Wirkung der Endokrinen Disruptoren Nonylphenol, OMC, 4-MBC und der Phytoöstrogene auf den Knochen der ovx Ratte im Mittelpunkt. Die ovx Ratte stellt dabei ein Modell für postmenopausale Frauen dar. Daraus soll abgeleitet werden, inwieweit sich die Osteoporose der Frauen in der Postmenopause durch Anwesenheit von Endokrinen Disruptoren in der Umwelt möglicherweise verstärkt. Zum Vergleich testeten wir den bekannten Effekt von 17ß-Estradiol auf den Knochen. Weiterhin soll festgestellt werden ob A-diol in diesem Versuch eine Wirkung auf den Knochen hat. Hierfür werden die genannten Substanzen weiblichen Sprague-Dawley-Ratten über 3 Monate per Futter verabreicht. Die verschiedenen Knochenparameter werden per pQCt vor und nach Ovarektomie unter der Futterapplikation gemessen.

Es wird im Vergleich mit 17ß-Estradiol untersucht, ob die in Sojaprodukten enthaltenen Isoflavone ein Fortschreiten der Osteoporose in der Postmenopause hemmen.

Die Unterschiede des Knochenumbaus in spongiösem und kortikalem Knochen in der Postmenopause sollen durch Vergleich der analysierten Knochenparameter untersucht werden.

\subsection{Futterverbrauch und Körpergewicht}

In der Menopause kommt es zu einem Abfall der Östrogenspiegel. Das kann zu einer Zunahme des Körperfettgewebes und somit zu einer Gewichtszunahme bei postmenopausalen Frauen führen (Lovejoy et al. 2008). Diese Aussage spiegelt sich in meinen Ergebnissen wider. Nach Ovx nimmt das Körpergewicht aller Tiere signifikant zu, nur die Tiere, welche eine E2-Substitution erhielten, zeigten keine signifikante Zunahme des Körpergewichts, das korreliert auch mit einem geringeren Futterverbrauch. ERaKnockout-Mäuse zeigen eine deutliche Zunahme des Fettgewebes, ERa ist also der dominante Rezeptor im Fettgewebe (Naaz et al. 2003). Es ist nach meinen Ergebnissen anzunehmen, dass E2 über eine Bindung an den ERa eine deutliche Zunahme des Fettgewebes bei der ovx Ratte verhindert. Die Gabe von sojahaltigem Futter mit darin enthaltenen Phytoöstrogenen bewirkt im Vergleich zur E2-Gruppe keine Reduktion der Körpergewichtszunahme nach Ovx. Dieses Ergebnis stimmt mit dem von Selvaraj et al. 
überein, in deren Studie ovx Mäusen ein Metabolit des Phytoöstrogens Daidzein appliziert wurde; das führte nicht zu einer Gewichtsreduktion und hatte keinen Einfluss auf das Fettgewebe (Selvaraj et al. 2004). Die Tiere, welche 4-MBC und OMC per Futter erhielten, wiesen eine im Vergleich zu den ovx Tieren signifikant geringere Zunahme des Körpergewichtes auf, allerdings nicht so ausgeprägt wie in der E2-Gruppe. Hier kann man vermuten, dass ebenfalls eine Bindung an den ERa stattgefunden haben könnte und somit die Gewichtszunahme nach Ovx nicht so ausgeprägt ist. Allerdings zeigt sich bei diesen Tieren keine passende Korrelation zum Futterverbrauch.

\subsection{Beurteilung der gemessenen Knochenparameter anhand der Ovx und 17 $\beta$-Estradiol Wirkung auf den Knochen}

Um die unterschiedlichen gemessenen Knochenparameter in Bezug auf ihre Aussagekraft über die Knocheneigenschaften in der Postmenopause beurteilen zu können, werden hier zunächst die Werte der E2-Gruppen mit denen der Ovx-Gruppen verglichen. Abb. 15 belegt, dass die Spongiosadichte nach Ovarektomie erwartungsgemäß deutlich abfältt. Der Abfall der Dichte des spongiösen Knochens ist in der E2-Gruppe signifikant geringer. Dieses Ergebnis bestätigt, dass postmenopausale Knochenveränderungen durch Östrogensubstitution verhindert oder zumindest reduziert werden (Turner et al. 1994). Die Spongiosadichte ist also ein geeigneter Parameter um postmenopausale Osteoporose zu diagnostizieren (Raisz 2005b). Lindberg et al. zeigten, dass der durch Östrogene induzierte antiosteoporotische Effekt bei weiblichen Mäusen durch ERa vermittelt wird (Lindberg et al. 2001). Nach unseren Messungen bestätigt sich die These einer Bindung von E2 an ERa im Knochen.

Die Spongiosamasse fällt in der Ovx-Gruppe ebenfalls wie erwartet deutlich ab (Abb. 19). Im Vergleich bewirkt die 17 $\beta$-Estradiol-Substitution trotz Ovx sogar einen signifikanten Anstieg der Spongiosamasse.

Die Dichte des kortikalen Knochens steigt nach Ovx allein und in der E2-Gruppe gleichermaßen an (Abb. 17). Laut Gasser et al. ist es auch nicht zu erwarten, dass sich die Kortikalisdichte durch Ovx stark verändert. Weiterhin hängen die Messwerte der Kortikalisdichte stark davon ab, wie weit distal des Kniegelenks gemessen wird (Gasser et al. 1995). Die Kortikalismasse erhöht sich ebenfalls in der E2-Gruppe sowie in der Ovx- 
Gruppe (Abb. 21), trotzdem ist die Kortikalismasse der Tiere der E2-Gruppe signifikant geringer als in der Ovx-Gruppe. In einer Studie von Gasser et al. wurde die proximale Tibiametaphyse bei 15 Monate alten Ratten per pQCT gemessen. In dieser genannten Studie wurde bereits 2 Wochen nach Ovx eine deutlich erniedrigte Kortikalismasse gemessen (Gasser et al. 1995). Wiederum in einer anderen pQCT Messung von Breen et al. wurde die proximale Tibia von ovx Ratten in vivo und nachfolgend ex vivo gemessen. Die dort gemessenen Parameter des kortikalen Knochens in vivo und ex vivo schwankten sehr stark und es bestand keine Korrelation zu einander (Breen et al. 1996). Zusammenfassend weisen sowohl Ovx allein als auch E2 keinen eindeutigen Effekt auf den kortikalen Knochen auf. Yoshiko et al. stellten fest, dass durch Ovx ausgelöster Östrogenmangel bevorzugt Knochenresorption in spongiösem Knochen verursacht, daher sei anzunehmen, dass Östrogen in erster Linie den Knochenumbau in der Spongiosa reguliert (Riggs et al. 2002). Diese Aussage erklärt zumindest den insgesamt geringen Effekt von Ovx und 17 $\beta$-Estradiol auf die Kortikalsdichte (Abb. 17) und die Kortikalismasse (Abb. 21).

Die endostale Fläche steigt in der Ovx-Gruppe wie in der E2-Gruppe an (Abb. 23). Gasser beschrieb, dass die Messwerte des pQCT Systems für die flächenbezogenen Querschnittswerte nicht genau seien, da es die Werte mit Hilfe eines planen $1 \mathrm{~mm}$ dicken Schnittes berechne und damit die dreidimensionale Struktur nicht berücksichtigt werde (Gasser 1995). In dieser Messung erhöht sich die endostale Fläche nach Ovx in allen Gruppen deutlich, es zeigt sich keine signifikante Wirkung durch alleinige E2-Gabe (Abb. 23). Nach Lind et al. korrelieren vor allem die Gesamtquerschnittsfläche des Knochens und die Fläche des kortikalen Knochens mit den mechanischen Eigenschaften des Knochens, wie der Härte und Stärke (Lind et al. 2001). Die Fläche der Kortikalis steigt nach Ovx allein minimal an, in der E2-Gruppe war im Vergleich eine signifikant niedrigere Fläche der Kortikalis zu messen (Abb. 25). Diese Resultate sprechen eindeutig dagegen, dass die Querschnittsfläche der Kortikalis mit den mechanischen Eigenschaften des Knochens korreliert, da zumindest beim Menschen in der Postmenopause hohe Östrogenspiegel mit einem geringeren Frakturrisiko einhergehen (Garnero et al. 2000, Kuchuk et al. 2007).

Aus den oben genannten Erkenntnissen resultiert, dass in erster Linie die Bewertung der Spongiosadichte und Spongiosamasse Aufschluss darüber geben, ob eine östrogene oder 
Östrogen-ähnliche Wirkung am Knochen erfolgt ist oder nicht.

Daher wird die Wirkung der Endokrinen Disruptoren und auch A-diol in erster Linie anhand dieser Knochenparameter bewertet.

Die Resultate bestätigen, dass postmenopausale Osteoporose zunächst hauptsächlich den spongiösen Knochen betrifft.

\subsection{Wirkung von A-diol auf den Knochen}

Androgenen wurde eine knochenprotektive Wirkung zugeschrieben, die AndrogenSerumspiegel postmenopausaler Frauen korrelieren positiv mit der Knochendichte (Buchanan et al. 1988). In den hier durchgeführten pQCT-Messungen zeigte A-diol in der hier verwendeten Dosierung keine Wirkung auf die Knochenparameter. Spongiosamasse und Spongiosadichte verhielten sich wie in der Ovx-Gruppe (Abb. 15 und Abb. 21). Knochenprotektive Effekte werden überwiegend über ERa vermittelt. Da A-diol in meiner Arbeit keinerlei Wirkung auf die gemessenen Knochenparameter zeigt, unterstützt dies die These, dass A-diol ein Ligand an ERß sein könnte (Wahlgren et al. 2008).

\subsection{Wirkung von Endokrinen Disruptoren}

\subsubsection{Wirkung von Phytoöstrogenen}

Phytoöstrogene haben einen positiven Einfluss auf den postmenopausalen Knochendichteverlust (Arena et al. 2002). In dieser Untersuchung war die Abnahme der Spongiosadichte in der Ovx-soy-Gruppe signifikant geringer als in der Ovx-Gruppe (Abb. 15 u. Abb 16). Dieses Ergebnis deckt sich mit den Resultaten von Mathea et al, die nachwiesen, dass Genistein und Dadizein die Knochendichte nach Ovx erhöhen (Mathey et al. 2007). Die Spongiosamasse stieg nach Ovx unter der Gabe von sojahaltigem Futter sogar diskret an, dieses Resultat ist signifikant gegenüber der Ovx-Gruppe. In einer veröffentlichten Studie erhielten Ratten für 3 Monate isoflavonreiches Futter. Zwei Monate nach Ovx war bei diesen Tieren die Knochenmasse ebenfalls erhöht (Tsuang et al. 2008). In einer Studie von Hertrampf et al. bewirkte Genistein über einen ERa abhängigen Mechanismus eine knochenprotektive Wirkung bei der ovx Ratte (Hertrampf et al. 2007). 
Die Phytoöstrogene zeigen auch nach meinen Ergebnissen wie erwartet eine knochenprotektive Wirkung. Der Effekt auf die gemessenen Knochenparameter ist ähnlich wie der des $17 \beta$-Estradiols, so dass eine Wirkung mit Bindung an den ERa im Knochen anzunehmen ist. Da in meiner Arbeit die jeweilige Wirkung der Einzelsubstanzen auf den Knochen im Vordergrund steht, wurde bewusst darauf verzichtet alle sojafreien Gruppen gegenüber den sojahaltigen Gruppen auf Signifikanzen zu testen.

\subsubsection{4-Nonylphenol}

4-Nonylphenol zeigt östrogene Aktivität in vivo und in vitro (Kwack et al. 2002).

Es konnte nachgewiesen werden, dass NP am isolierten Maus Uterus Östrogenrezeptor bindet (Shelby et al.1996). In unserer Untersuchung der Knochenparameter bewirkt die Applikation von NP in hoher Dosierung einen im Vergleich zu den ovx Tieren signifikant geringeren Abfall der Spongiosamasse und Spongiosadichte der Tiere (Abb. 19 und Abb. 15). Alle anderen Knochenparameter werden nicht beeinflusst.

Laut Safe et al bindet 4-Nonylphenol an ERa und ERß ( Safe et al. 2001). Tollefsen et al. belegten bei Regenbogenforellen, dass 4-Nonylphenol mit 17 $\beta$-Estradiol um die Bindung an den ERa konkurriert (Tollefsen et al. 2002). Da am Knochen vor allem ERa östrogene Wirkung vermittelt, ist es auch nach meinen Ergebnissen möglich, dass NP in der Lage ist an diesen ER zu binden. Der Effekt von NP high ist aber vergleichsweise nicht annähernd so stark wie der von E2. Das ist in anderen Studien vorbeschrieben (Safe et al. 2002). Eine Wirkung auf den Knochen über andere Mechanismen als den ERa ist nicht ausgeschlossen. Das stimmt mit der Aussage überein, dass NP zwar östrogene Wirkung u.a. auch durch Bindung an ER zeigt, diese allerdings in verschiedenen Organen unterschiedlich ausgeprägt ist (Watanabe et al. 2004).

Da NP in der geringeren Dosierung keinen Effekt zeigt, scheint hier die gegebene Substanzmenge zu niedrig zu sein. Es wäre interessant zu sehen, ob NP in einer noch höheren Dosierung als hier gewählt einen stärkeren östrogenen Effekt auf den Knochen hat.

Bei den Tieren, die sojahaltiges Futter erhielten, fällt unter NP-Applikation auf, dass sowohl Knochendichte als auch Knochenmasse signifikant niedriger sind als bei den ovx Tieren (Abb. 16 und Abb.20). Dieser im Vergleich starke Abfall war nicht erwartet worden. 
Möglicherweise verhindert die Anwesenheit von NP eine Bindung von Phytoösttrogenen an den ERa. Aufgrund dieses unerwarteten Ergebnisses sind jedoch auch Messfehler nicht auszuschließen.

\subsubsection{Wirkung der UV-Filter OMC und 4-MBC auf den Knochen}

Die UV-Filter OMC und 4-MBC zeigen östrogene Aktivität in vivo und in vitro (Schlumpf et al. 2001). Die orale Applikation von OMC hat sowohl in niedriger als auch in hoher Dosierung keinen Effekt auf die Spongiosadichte (Abb. 15) oder auf die Spongiosamasse (Abb. 19). OMC weist nach unseren Ergebnissen also keinerlei östrogene Wirkung auf den Knochen auf, so dass eine Bindung von OMC an ERa ausgeschlossen erscheint.

4-MBC bewirkt in den durchgeführten Messungen durchaus östrogene Effekte.

In der 4-MBC-low- und in der 4-MBC-high-Gruppe war der Abfall der Spongiosadichte signifikant geringer als in der Ovx-Gruppe (Abb. 15), also ähnlich der E2-Wirkung. Gleiches gilt für die Spongiosamasse. In der 4-MBC-low- und in der 4-MBC-high-Gruppe waren die Werte signifikant höher als in der Ovx-Gruppe, wieder vergleichbar mit der E2Gruppe (Abb. 21). Diese Resultate passen zu der Erkenntnis von Schlumpf et al., dass 4MBC mehr östrogene Aktivität zeigt als andere UV Filter (Schlumpf et al. 2001), da 4-MBC hier im Vergleich zu OMC eine deutliche östrogene Wirkung hat. Nach den Resultaten der Beeinflussung der Spongiosadichte und der Spongiosamasse durch 4-MBC wäre es möglich, dass 4-MBC an Östrogenrezeptoren im Knochen bindet und wie E2 wirkt. Beweisen ließe sich diese Aussage selbstverständlich nur durch molekularbiologische Methoden. Laut Schlumpf et al. ist 4-MBC in der Lage an rekombinanten humanen ERß zu binden, eine Bindung an ERa konnte nicht nachgewiesen werden (Schlumpf et al. 2004a). Die östrogene Wirkung am Knochen wird jedoch über ERa vermittelt (Vidal et al. 2000). Da 4-MBC in unseren Messungen eine dem E2 sehr ähnliche Wirkung zeigt, ist nach den vorliegenden Ergebnissen eine Bindung von 4-MBC an ERa anzunehmen. Da 4-MBC also die Spongiosamasse und die Spongiosadichte in der Postmenopause ähnlich wie E2 erhöht, wäre dieser Effekt zunächst positiv zu bewerten, da der Knochenmasseverlust und Knochendichteverlust ja durch 4-MBC geringer ist. Jedoch lässt sich durch die gemessenen Knochenparameter keine Aussage über die Qualität des Knochens und ein nachfolgendes Frakturrisiko treffen. Weiterhin ist zu bedenken, dass der Mensch in der Umwelt einer Mischung von Endokrinen Disruptoren ausgesetzt ist. Kombinationen aus mehreren UV-Filtern zeigen durchaus synergistische Effekte (Kunz und Fent 2006). 


\section{Zusammenfassung}

In meiner Arbeit wurde die Wirkung von den Endokrinen Disruptoren 4-MBC, OMC, NP und Phytoöstrogenen sowie 17 $\beta$-Estradiol und A-diol auf den Knochen der ovarektomierten Ratte untersucht. Die ovarektomierte Ratte ist ein etabliertes Modell für postmenopausale Osteoporose. Durch diesen Versuch sollte festgestellt werden, ob Endokrine Disruptoren eine Wirkung auf die Knochen von postmenopausalen Frauen haben. Daraus resultierend sollte abgeleitet werden, ob ED den postmenopausalen Knochenabbau verstärken bzw. beeinflussen und insbesondere die Phytoöstrogene diesen hemmen.

Bei den Tieren, die ausschließlich sojafreies Haltungsfutter erhielten, fiel die Spongiosadichte des Knochens nach Ovarektomie wie erwartet deutlich ab, durch Applikation von 17ß-Estradiol per Futter konnte der Knochendichteverlust nach Ovarektomie deutlich reduziert werden. Diese erwarteten Effekte bestätigen, dass die ovarektomierte Ratte ein geeignetes Versuchsmodell für Knochenveränderungen der postmenopausalen Frau ist.

A-diol zeigt im Vergleich zu 17ß-Estradiol in dieser Untersuchung keine Wirkung auf den Knochen. Eine Bindung an ERa scheint somit ausgeschlossen und unterstützt die These, dass A-diol ein Ligand an ERß ist.

4-MBC zeigt nach meinen Ergebnissen eindeutig Östrogen-ähnliche Effekte auf den spongiösen Knochen. Nach Ovarektomie fielen die Spongiosadichte sowie die Spongiosamasse in den 4-MBC-Gruppen signifikant geringer ab als in der Ovx-Gruppe, ähnlich wie in den E2-Gruppen. Der Effekt verstärkt sich noch durch die höhere Dosierung.

Eine Bindung von 4-MBC an ERa im Knochen und daraus resultierende östrogene Wirkung ist damit durchaus anzunehmen.

NP bewirkt in der höheren Dosierung Östrogen-ähnliche Wirkung am Knochen, allerdings deutlich schwächer als $17 \beta$-Estradiol, so dass hier offensichtlich eine dosisabhängige Wirkung besteht. OMC zeigt in den hier verwendeten Dosierungen keine Östrogenähnliche Wirkung am Knochen. 4-MBC hat also im Vergleich zu NP und OMC die größte östrogene Wirkung auf den Knochen. Inwieweit die Wirkung von 4-MBC auf die Spongiosadichte mit der Stabilität des Knochens korreliert, lässt sich hier nicht feststellen. Phytoöstrogene sollen ebenfalls knochenprotektive Eigenschaften ähnlich den Östrogenen 
besitzen und postmenopausale Osteoporose also positiv beeinflussen.

Diese These lässt sich nach den hier erstellten Ergebnissen bestätigen. Der Abfall der Spongiosadichte nach Ovarektomie ist unter Phytoöstrogenapplikation signifikant geringer. Die Wirkung ist ähnlich der des $17 \beta$-Estradiols, jedoch nicht so stark ausgeprägt. Eine Bindung von Phytoöstrogenen an ERa des Knochens ist daher nahezu bestätigt.

Von den hier per PQCT gemessenen Knochenparametern weisen nur die Masse und Dichte des spongiösen Knochens die erwarteten Veränderungen auf. Selbst 17ß-Estradiol hat keinen Effekt auf die kortikalen Knochenparameter. Dies bestätigt, dass sich postmenopausale Veränderungen schneller am spongiösen Knochen zeigen.

Spongiosamasse und Spongiosadichte sind entsprechend den Ergebnissen meiner Arbeit die geeignetsten Knochenparameter zur Osteoporose-Beurteilung.

Zusammenfassend kann gesagt werden, dass sich der durch die Ovarektomie verursachte Östrogenmangel nach 12 Wochen deutlich an der Tibiametaphyse darstellt.

Durch Substitution von 17ß-Estradiol und Phytoöstrogenen konnte der Knochendichteverlust gemindert werden.

Als Endokriner Disruptor zeigte 4-MBC deutlich östrogene Wirkung auf den postmenopausalen Knochen, wohingegen NP nur geringen und OMC keinen Einfluss auf die Knochenparameter hat.

Da die Kombination von NP und Phytoöstrogenen einen anderen Effekt zeigt als die Gabe der Einzelsubstanzen, wären Untersuchungen interessant, in denen eine Kombination mehrerer verschiedener Endokriner Disruptoren verabreicht wird. 


\section{Literaturverzeichnis}

Ahel M, McEvoy J,Giger W (1993):

Bioaccumulation of the lipophilic metabolites of nonionic surfactants in freshwater organisms.

Environ Pollut 79(3), 243-8

Alekel DL, St German A, Peterson CT, Hanson KB, Stewart JW, Toda T (2000): Isoflavone-rich soy protein isolate attenuates bone loss in the lumbar spine of perimenopausal women.

Am J Clin Nutr $\underline{72}, 844-52$

Arena S, Rappa C, Del Frate E, Cenci S, Villani C (2002):

(Anatural alternative to menopausal hormone replacement therapy-Phytoestrogens). Minerva Ginecol $\underline{54}(1), 53-7$

Bartl R, Bartl C:

Osteoporose-Manual. 1.Auflage;

Springer Verlag, Wien 2004, S.25

Beardsworth SA, Kearny CE, Purdie DW (1999):

Prevention of postmenopausal bone loss at lumbar spine and upper femur with tibolone: a two-year randomised controlled trial.

Br J Obstet Gynaecol 106 (7), 678-83

Bennie DT (1999):

Review of the environmental occurrence of alkylphenols and alkylphenol ethoxylates. Water Qual Res J Canada 34(1), 79-122

Bland R (2000):

Steroid hormone receptor expression and action in bone.

Clin Sci 98(2), 217-40

Blom A, Ekman E, Johannisson A, Norrgren L, Pesonen M (1998):

Effects of xenoestrogenic environmental pollutants on the proliferation of a human breast cancer cell line (MCF-7).

Arch Environ Contam Toxicol 34(3), 306-10

Braidman IP, Davenport LK, Carter DH, Selby PL, Mawer EB, Freemont AJ (1995): Preliminary in situ identification of estrogen target cells in bone.

J Bone Miner Res $\underline{10}(1), 74-80$

Breen SA, Millest AJ, Loveday BE, Johnstone D, Waterton JC (1996):

Regional Analysis of Bone Mineral Density in the Distal Femur and Proximal Tibia Using Peripheral Quantitative Computed Tomography in the Rat In Vivo.

Calcif Tissue Int 토, 449-453 
Buchanan JR, Myers C, Lloyd T, Leuenberger P, Demers LM (1988):

Determinants of peak trabecular bone density in women: the role of androgens, estrogen, and exercise.

J Bone Miner Res $\underline{3}(6), 673-680$

Carlsen E, Giwercam A, Keiding N, Skakkebaek NE (1992):

Evidence for decreasing quality of semen during pat 50 years.

BMJ $\underline{\text { 305}}(6854), 609-13$

Cheek AO, Kow K, Chen J, McLachlan JA (1999):

Potential Mechanismus of Thyroid Disruption in Humans: Interaction of

Organochlorine Compounds with Thyroid Receptor, Transthyretin, and Thyroidbinding Globulin.

Environ Health Perspect 107, 273-278

Chow J, Tobias JH, Colston KW, Chambers TJ (1992):

Estrogen maintains trabecular bone volume in rats not only by suppression of bone resorption but also stimulation of bone formation.

J Clin Invest 89(1), 74-8

Colborn T (2006):

A case for revisiting the safety of pesticides: a closer look at neurodevelopment.

Environ Health Perspect 114(1),10-7

Dankwardt A:

Hormonell und reproduktionstoxisch wirksame Pestizide.

Umweltstiftung WWF-Deutschland, Franfurt am Main 1998

Danzo BJ (1998):

The effects of environmental hormones on reproduction.

Cell Mol Life Sci $\underline{54}, 1249-1264$

Doerge DR, Twaddle NC, Churchwell MI, Chang HC, Newbold RR, Delclos KB (2002):

Mass spectrometric determination of p-nonylphenol metabolism and disposition following oral administration to Sprague-Dawley rats.

Reprod Toxicol 16,(1), 45-46

Durrer S, Maerkel K, Schlumpf M, Lichtensteiger W (2005):

Estrogen Target Gene Regulation and Coactivator Expression in Rat Uterus after Developmental Exposure to the Ultraviolet Filter 4-Methylbenzylidene Camphor. Endocrinology 146 (5), 2130-2139

DVO-Leitlinie 2009 zur Prophylaxe, Diagnostik und Therapie der Osteoporose bei Erwachsenen, Dachverband Osteologie e.V., www.dv-osteologie.org/dvo_leitlinien/dvo-leitlinie-2009 
Eastell R:

Chapter 50.Pathogenesis of Postmenopausal Osteoporosis; In: Primer on the metabolic bone diseases and disorders of mineral metabolism, 5.Auflage, hrsg.v. Favus MJ; American society for bone and mineral research, Washington DC 2003, S.314-316

Ekelund R, Bergman A, Granmo A, Berggren M (1990):

Bioaccumulation of 4-nonylphenol in marine animals-a reevaluation.

Environ Pollut $\underline{64}(2), 107-20$

Ferretti JL:

Chapter 25 : Peripheral Quantitative Computed Tomography (pQCT) for Evaluating structural and mechanical properties of small bone, In: Practical Guide for Mechanical Testing of Bone, hrsg.v. An YH, Draughn RA; CRC Press, Boca Raton 1999, S.1-25

Ferretti JL, Capozza RF, Zanchetta JR (1996):

Mechanical Validation of a Tomographic (pQCT) Index for Noninvasive Estimation of Rat Femur Bending Strength.

Bone $\underline{18}, 97-102$

Fogelmann I, Blake GM (2005):

Bone densitometry: an update.

Lancet 366(9503), 2068-70

Frost HM, Jee WS (1992):

On the rat model of human osteopenias and osteoporoses.

Bone Miner 18(3), 227-36

Gaido KW, Leonard LS, Lovell S, Gould JC, Babai D, Portier CJ, Mc Donell DP (1997):

Evaluation of chemicals with endocrine modulating activity in a yeast-based steroid hormone receptor gene transcription assay.

Toxicol Appl Pharmacol 143(1), 205-12

Gallagher AC, Chambers TJ, Tobias JH (1996):

Androgens contribute to the stimulation of cancellous bone formation by ovarian hormones in female rats.

Am J Physiol 270, 407-12

Gallagher JC :

Chapter 53.Effect of Estrogen on Bone; In: Primer on the Metabolic Bone Diseases and Disorders of Mineral Metabolism, 5. Auflage, hrsg.v. Favus MJ; American society for bone and mineral research, Washington DC 2003, S.327-332 
Garnero P, Sornay-Rendu E, Delmas PD (2000):

Low serum IGF-1 and occurrence of osteoporotic fractures in postmenopausal women.

Lancet $\underline{355}$ (9207), 898-899

Gasser JA (1995):

Assessing bone quantity by $\mathrm{PQCT}$.

Bone 17, 14555-1545

Gomez E, Pillon A, Fenet H, Rosain D, Duchesne MJ, Nicolas JC, Balaguer P, Casellas C (2005):

Estrogenic activity of cosmetic components in reporter cell lines: parabens, UV screens, and musks.

J Toxicol Environ Health A $\underline{68}(4), 239-51$

Guenther K, Heinke V, Thiele B, Kleist E, Prast H, Raecker T (2002):

Endocine Disrupting Nonylphenols are ubiquitous in Food.

Environ Sci Technol $\underline{36}$, 1676-1680

Hammond B, Katzenellenbogen BS, Krauthammer N, McConell J (1979):

Estrogenic activity of the insecticide chlordecone (Kepone) and interaction with uterine estrogen receptors.

Proc Natl Acad Sci USA $\underline{76}(12), 66451-5$

Han D, Denison MS, Tachibana H, Yamada K (2002):

Relationship betwen Estrogen Receptor-Binding and Estrogenic Activities of Environmental Estrogens and Suppression by Flavonoids.

Biosci Biotechnol Biochem $\underline{66}(7), 1479-1487$

Handa RJ, Pak TR, Kudwa AE, Lund TD, Hinds L (2008):

An alternative pathway for androgen regulation of brain function: activation of estrogen receptor beta by the metabolite of dihydrotestosterone, 5alpha-androstane3beta,17beta-diol.

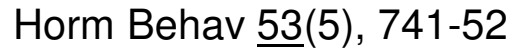

Hayden C, Roberts MS, Benson H (1997):

Systemic absorption of sunscreen after topical application.

Lancet $\underline{350}, 863-864$

Heimler I, Rawlins RG, Owen H, Hutz RJ (1998):

Dioxin Perturbs, in a Dose- and Time-Dependent Fashion, Steroid Secretion, and Induces Apoptosis of Human Luteiized Granulose Cells.

Endocrinology 139(10), 4373-4379

Hertrampf T, Gruca MJ, Seibel J, Laudenbach U, Fritzemeier KH, Diel P (2007):

The bone-protective effect of the phytoestrogen genistein is mediated via ER alphadependent mechanisms and strongly enhanced by physical activity.

Bone $\underline{40}(6), 1529-35$ 
Inoue K, Kondo S, Yoshie Y, Kato K, Yoshimura Y, Horie M, Nakazawa H (2001): Migration of 4-nonylphenol from polyvinyl chloride food packaging films into food simulants and foods.

Food Addit Contam 18(2), 157-64

Jobling S, Reynolds T, White R, Parker MG, Sumpter JP (1995):

A variety of environmentally persistent chemicals, including some phthalate plasticizers, are weakly estrogenic.

Environ Health Perspect 103(6), 582-7

Komm BS, Terpening CM, Benz DJ, Graeme KA, Korc M, Greene GL, O`Malley BW, Haussler MR (1988):

Estrogen binding, receptor mRNA, and biologic response in ostoblast-like osteosarcoma cells.

Science 241(4861), 81-4

Kuchuk NO, van Schoor NM, Pluijm SM, Smit JH, de Ronde W, Lips P (2007):

The association of sex hormone levels with quantitative ultrasound, bone mineral density, bone turnover and osteoporotic fractures in older men and women.

Clin Endocrinol (Oxf) 67(2), 295-303

Kuiper G, Carlsson B, Grandien K, Enmark E, Häggblad J, Nilsson S, Gustafsson J (1997):

Comparison of the Ligand Binding Specifity and Transcript Tissue Distribution of Estrogen Receptors $\alpha$ and $\beta$.

Endocrinology $\underline{138}$, 863-870

Kuiper G, Lemmen J, Carlsson B, Corton J, Safe S, van der Saag P, van der Burg B, Gustafsson J (1998):

Interaction of Estrogenic Chemicals and Phytoestrogens with Estrogen Receptor $\beta$. Endocrinology 139, 4252-4263

Kunz PY, Fent K (2006):

Estrogenic activity of UV filter mixtures.

Toxicol Appl Pharmacol 217(1), 86-99

Kwack SJ, Kwon O, Kim HS, Kim SS, Kim SH, Sohn KH, Lee RD, Park CH, Jeung EB, An BS et al. (2002):

Comparative evaluation of alkylphenolic compounds on estrogenic activity in vitro and in vivo.

J Toxicol Environ Health A $\underline{65}(5-6), 419-31$

Lee K, Jessop H, Suswillo R, Zamann G, Lanyon L (2003):

Endocrinology: bone adaptation requires oestrogen receptor-alpha.

Nature $\underline{424}(6947), 389$ 
Lind PM, Lind L, Larsson S, Örberg J (2001):

Torsional Testing and Peripheral Quantitative Computed Tomography in Rat Humerus.

Bone 29, 265-270

Lindberg MK, Alatalo SL, Halleen JM, Mohan S, Gustafsson JA, Ohlsson C (2001): Estrogen receptor specificity in the regulation of the skeleton in female mice.

J Endocrinol 171(2), 229-236

Longnecker MP, Rogan WJ, Lucier G (1997):

The human health effects of DDT (dichlorodiphenyltrichlorethane) and PCBS (polychlorinated biphenyls) and an overview of organochlorines in public health. Annu Rev Public Health $\underline{18}$, 211-44

Lovejoy JC, Champagne CM, de Jonge L, Xie H, Smith SR (2008) : Increased visceral fat and decreased energy expenditure during the menopausal transition.

Int J Obes (Lond) 32(6), 949-958

Mathey J, Mardon J, Fokialakis N, Puel C, Kati-Coulibaly S, Mitakou S, BennetauPelissero C, Lamothe V, Davicco MJ, Lebecque P (2007):

Modulation of soy isoflavones bioavailability and subsequent effects on bone health in ovariectomized rats: the case for equol.

Osteoporos Int 18(5), 671-9

Mc Donnell DP, Norris J (2002):

Connections and Regulation of the Human Estrogen Receptor.

Science 296(5573), 1642-1644

Morito K, Hirose T, Kinjo J, Hirakaea T, Okawa M, Nohara T, Ogawa S, Inoue S, Muramatsu M, Masamune Y (2001):

Interaction of phytoestrogens with estrogen receptors alpha and beta.

Biol Pharm Bull 24(4), 351-6

Mueller SO, Kling M, Arifin Firzani P, Mecky A, Duranti E, Shields-Botella J, Delansorne R, Broschard T, Kramer PJ (2003):

Activation of estrogen receptor alpha and ERbeta by 4-methylbenzylidene-camphor in human and rat cells: comparison with phyto- and xenoestrogens.

Toxicol Lett 142(1-2), 89-101

Müller S, Schlatter C (1998):

Oestrogenic potency of nonylphenol in vivo-a case study to evaluate the relevance oh human non-occupational exposure.

Pure Appl Chem 70(9), 1874-1853 
Naaz A, Zakroczymski M, Heine P, Taylor J, Saunders P, Lubahn D, Cooke PS (2003):

Effect of ovariectomy on adipose tissue of mice in the absence of estrogen receptor alpha (ERalpha): a potential role for estrogen receptor beta (ERbeta).

Horm Metab Res 35(4), 271

Nagel SC, vom Saal F, Thayer RA, Dhar MG, Boechler M, Welshons WV (1997):

Relative Binding Affinity-Serum Modified Access (RBA-SMA) Assay Predicts the

Relative in Vivo Bioactivity of the Xenoestrogens Bisphenol A and Octylphenol.

Environ Health Perspect 105, 70-76

Nagtegaal M, Ternes T, Baumann W, Nagel R (1997):

UV-Filtersubstanzen in Wasser und Fischen.

UWSF-Z, Umweltchem. Ökotox. $\underline{9}, 79-86$

Nicolopoulou-Stamati P, Pitsos MA (2001):

The impact of endocrine disruptors on the female reproductive system.

Hum Reprod Update $\underline{7}(3)$, 323-330

Odum J, Lefevre PA, Tittensor S, Paton D, Routledge EJ, Beresford NA, Sumpter JP, Ashby J (1997):

The rodent uterotrophic assay: critical protocol features, studies with nonyl phenols, and comparison with a yeast estrogenicity assay.

Regul Toxicol Pharmacol 25(2), 176-88

Onoe Y, Miyaura C, Ohta H, Nozawa S, Suda T (1997):

Expression of Estrogen Receptor $\beta$ in Rat Bone.

Endocrinology 138(10), 4509-12

Ornoy A, Giron S, Aner R, Goldstein M, Boyan BD, Schwartz Z (1994) :

Gender dependent effects of testosterone and 17 beta-estradiol on bone growth and modelling in young mice.

Bone Miner 24(1), 43-58

Pacifci R (1996) :

Estrogen, cytokines, and pathogenesis of postmenopausal osteoporosis.

J Bone Miner Res 11(8), 1043-51

Paris F, Balaguer P, Terouanne B, Servant N, Lacoste C, Cravedi JP, Nicolas JC,

Sultan C (2002):

Phenylphenols, biphenols, bisphenol-A and 4-tert-octylphenol exhibit alpha and beta estrogen activities and antiandrogen activity in reporter cell lines.

Mol Cell Endocrinol 193(1-2), 43-9

Patlak M (2001):

Bone builders: the discoveries behind preventing and treating osteoporosis.

FASEB J. 15(10), 1677E-E 
Peacock M, Turner CH, Econs M, Forud T (2002):

Genetics of Osteoporosis.

Endocr Rev 23, 303-326

Pensler JM, Radosevich JA, Higbee R, Langman CB (1990):

Osteoclasts isolated from membranous bone in children exhibit nuclear estrogen and progesterone receptors.

J Bone Miner Res $\underline{5}(8), 797-802$

Pettersson H, Holmberg L, Axelson M, Norlin M (2008):

CYP7B1-mediated metabolism of dehydroepiandrosterone and 5alpha-androstane3beta, 17beta-diol-potential role(s) for estrogen signaling.

FEBS J $\underline{\text { 275 }}(8)$, 1778-89

Potter SM, Baum JA, Teng H, Stilmann RJ, Shay NF, Erdmann JW (1998):

Soy protein and isoflavones: their effects on blood lipids and bone density in postmenopausal women.

Am J Clin Nutr $\underline{68}, 1375-1379$

Prestwood KM, Pilbeam CC, Burleson JA, Woodiel FN, Delmas PD, Deftos LJ, Raisz LG (1994):

The short-term essects of conjugated estrogen bone turnover in older women.

J Clin Endocrinol Metab 79(2), 366-71

Raisz LG (2005a):

Clinical practice. Screening for osteoporosis.

N Engl J Med 353(2), 164-71

Raisz LG (2005b):

Pathogenesis of osteoporosis:concepts, conflicts, and prospects.

J Clin Invest 115, 3318-3325

Riggs BL, Khosla S, Melton LJ $3^{\text {rd }}$. (2002):

Sex steroids and the construction and cnservation of the adult skeleton.

Endocr Rev 23(3), 279-302

Safe SH, Pallaroni L, Yoon K, Gaido K, Ross S, Saville B, McDonnell D (2001):

Toxicology of environmental estrogens.

Reprod Fertil Dev 13(4), 307-315

Safe SH, Pallaroni L, Yoon K, Gaido K, Ross S, McDonnell D (2002):

Problems for risk assessment of endocrine-active estrogenic compounds.

Environ Health Perspect 110(6), 925-9

Schlumpf M, Lichtensteiger W (1996):

Hormonaktive Xenobiotika.Störungen von Fortpflanzungs- und

Entwicklungsprozessen. UWSF Z Umweltchem Ökotox. $\underline{8}(6), 321-332$ 
Schlumpf M, Cotton B, Consience M, Haller V, Steinmann B, Lichtensteiger W (2001):

In vitro and in vivo Estrogenicity of UV Screens.

Environ Health Perspect $\underline{109}$, 239-244

Schlumpf M, Jarry H, Wuttke W, Ma R, Lichtensteiger W (2004a):

Estrogenic activity and estrogen receptor beta binding of the UV filter 3-benzylidene camphor. Comparison with 4-methylbenzylidene camphor.

Toxicology 199(2-3), 109-20)

Schlumpf M, Schmid P, Durrer S, Conscience M, Maerkel K, Henseler M, Gruetter M, Herzog I, Reolol S, Ceccatelli R et al. (2004b):

Endocrine activity and developmental toxicity of cosmetic UV filters-an update.

Toxicology 205(1-2), 113-122

Schmutzler C, Ambrugger P, Huhne K, Grüters A, Köhrle J (2004):

Endocrine Disrupters inhibit human thyroid peroxidase activity.

Exp Clin Endocrinol Diab 112(Suppl. 1), 54

Selvaraj V, Zakroczymski MA, Naaz A, Mukai M, Ju YH, Doerge DR, Katzenellenbogen JA, Helferich WG, Cooke PS (2004):

Estrogenicity of the isoflavone metabolite equol on reproductive and nonreproductive organs in mice.

Biol Reprod 71(3), 966-972

Shelby MD, Newbold RR, Tully DB, Chae K, Davis VL (1996):

Assessing Environmental Chemicals for Estrogenicity using a combination of in vitro and in vivo assays.

Environ Health Perspect 104, 1296-1300

Somekawa Y, Chiguchi M, Ishibashi T, Aso T (2001):

Soy intake related to menopausal symptoms, serum lipids, and bone mineral density in postmenopausal japanese women.

Obstet Gynecol 97, 109-15

Soto AM, Justicia H, Wray JW, Sonnenschein C (1991):

p-Nonyl-phenol: an estrogenic xenobiotic released from „modified“ polystyrene.

Environ Health Perspect 92, 167-73

Soto AM, Sonnenschein C, Chung KL, Fernandez MF, Olea N, Serrano FO (1995):

The E-SCREEN assay as a tool to identify estrogens: an update on estrogenic environmental pollutants.

Environ Health Perspect 103(7), 113-22

Sumpter JP, Jobling S (1995):

Vitellogenesis as a Biomarker for Estrogenic Contamination on the Aquatic

Environment.

Environ Health Perspect 103(7), 173-178 
Sunyer T, Lewls J, Collin-Osdoby P, Osdoby P (1999):

Estrogen`s bone protective effects may involve differential IL-1 receptor regulation in human osteoclast-like cells.

J Clin Invest 103(10), 1409-18

Tapiero H, Nguyen Ba G., Tew KD (2002):

Estrogens and environmental estrogens.

Biomed Pharmacother $\underline{56}$, 36-44

Terasaka S, Aita Y, Inoue A, Hayashi S, Nishigaki M, Aoyagi K, Sasaki H, WadaKiyama Y, Sakuma Y, Akaba S et al. (2004):

Using a Customized DNA Microarray for Expression Profiling of the EstrogenResponsive Genes to Evaluate Estrogen Activity among Natural Estrogens and Industrial Chemicals.

Environ Health Perspect 112, 773-781

Tollefsen KE, Mathisen R, Stenersen J (2002):

Estrogen mimics bind with similar affinity and specificity to the hepatic estrogen receptor in Atlantic salmon (Salmo salar) and rainbow trout (Oncorhynchus mykiss). Gen Comp Endocrinol 126(1), 14-22

Tsuang YH, Chen LT, Chiang CJ, Wu LC, Chiang YF, Chen PY, Sun JS, Wang CC (2008):

Isoflavones prevent bone loss following ovariectomy in young adult rats.

J Orthop Surg Res $\underline{3}, 3-12$

Turner RT, Riggs BL, Spelsberg TC (1994):

Skeletal Effects of Estrogen.

Endocr Rev 15(3), 275-300

Vidal O, Kindblom LG, Ohlsson C (1999):

Expression and localization of estrogen receptor-beta in murine and human bone. J Bone Miner Res 14(6), 923-9

Vidal O, Lindberg MK, Hollberg K, Baylink DJ, Andersson G, Lubahn DB, Mohan S, Gustafsson JA, Ohlsson C (2000):

Estrogen receptor specifity in the regulation of skeletal growth and maturation in male mice.

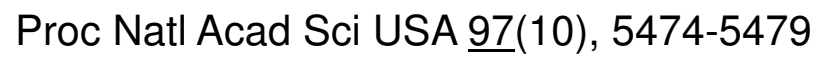

Wahlgren A, Svechnikov K, Strand ML, Jahnukainen K, Parvinen M, Gustafsson JA, Söder O (2008):

Estrogen receptor beta selective ligand 5alpha-Androstane-3beta, 17beta-diol stimulates spermatogonial deoxyribonucleic acid synthesis in rat seminiferous epithelium in vitro.

Endocrinology 149(6), 2917-22 
Watanabe H, Suzuki A, Goto M, Lubahn DB, Handa H, Iguchi T (2004):

Tissue-specific estrogenic and non-estrogenic effects of a xenestrogen, nonylphenol. J Mol Endocrinol 33(1), 243-252

Weihua Z, Lathe R, Warner M, Gustafsson JA (2002):

An endocrine pathway in the prostate, Erbeta, AR, 5alpha-androstane-3beta, 17betadiol, and CYP7B1, regulates prostate growth.

Proc Natl Acad Sci USA 99(21), 13589-94

White R, Jobling S, Hoare SA, Sumpter JP, Parker MG (1994):

Environmentally persistent Alkylphenolic Compounds are estrogenic.

Endocrinology 135, 175-182

Whitten PL, Patisaul HB (2001):

Cross-Species and Interassay Comparisons of Phytoestrogen Action.

Environ Health Perspect $\underline{109}$, 5-20

Wronski TJ, Cintron M, Dann LM (1988):

Temporal relationship between bone loss and increased bone turnover in ovariectomized rats.

Calcif Tissue Int $\underline{43}(3), 179-83$

Ying GG, Williams B, Kookana R (2002):

Environmental fate of alkylphenols and alkylphenol ethoxylates-a review.

Environ Int 28 (3), 215-26

Zalko D, Costagliola R, Dorio C, Rathahao E, Cravedi JP (2002):

In vivo metabolic fate of the xeno-estrogen 4-N-Nonylphenol in wistar rats.

Drug Metab Dispos 31(2), 168-78 


\section{Abbildungsverzeichnis}

Abbildung 1: 10

Abbildung 2: 10

Abbildung 3: 12

Abbildung 4: 13

Abbildung 5: 13

Abbildung 6: 13

Abbildung 7: 16

Abbildung 8: 17

Abbildung 9: 21

Abbildung 10: 22

Abbildung 11: 24

Abbildung 12: 24

Abbildung 13: 26

Abbildung 14: 26

Abbildung 15: 28

Abbildung 16: 28

Abbildung 17: $\quad 30$

Abbildung 18: 30

Abbildung 19: 32

Abbildung 20: $\quad 32$

Abbildung 21: $\quad 34$

Abbildung 22: $\quad 34$

Abbildung 23: $\quad 36$ 
Abbildung 24: 36

Abbildung 25: $\quad 38$

Abbildung 26: $\quad 38$

\section{Tabellenverzeichnis}

Tabelle 1: $\quad 20$

Tabelle 2: $\quad 20$

Tabelle 3: 23 